\title{
Design and optimization of a novel system for trigeneration
}

\author{
Arabkoohsar, Ahmad; Bruun Andresen, Gorm \\ Published in: \\ Energy
}

DOI (link to publication from Publisher):

10.1016/j.energy.2018.11.086

Creative Commons License

CC BY-NC-ND 4.0

Publication date:

2019

Document Version

Accepted author manuscript, peer reviewed version

Link to publication from Aalborg University

Citation for published version (APA):

Arabkoohsar, A., \& Bruun Andresen, G. (2019). Design and optimization of a novel system for trigeneration. Energy, 168, 247-260. https://doi.org/10.1016/j.energy.2018.11.086

\section{General rights}

Copyright and moral rights for the publications made accessible in the public portal are retained by the authors and/or other copyright owners and it is a condition of accessing publications that users recognise and abide by the legal requirements associated with these rights.

- Users may download and print one copy of any publication from the public portal for the purpose of private study or research.

- You may not further distribute the material or use it for any profit-making activity or commercial gain

- You may freely distribute the URL identifying the publication in the public portal -

\section{Take down policy}

If you believe that this document breaches copyright please contact us at vbn@aub.aau.dk providing details, and we will remove access to the work immediately and investigate your claim. 


\title{
Accepted Manuscript
}

Design and optimization of a novel system for trigeneration

\author{
A. Arabkoohsar, G.B. Andresen
}

PII:

S0360-5442(18)32297-7

DOI: $\quad$ https://doi.org/10.1016/j.energy.2018.11.086

Reference: EGY 14184

To appear in: Energy

Received Date: 30 April 2018

Revised Date: 23 October 2018

Accepted Date: 20 November 2018

Please cite this article as: Arabkoohsar A, Andresen GB, Design and optimization of a novel system for trigeneration, Energy (2018), doi: https://doi.org/10.1016/j.energy.2018.11.086.

This is a PDF file of an unedited manuscript that has been accepted for publication. As a service to our customers we are providing this early version of the manuscript. The manuscript will undergo copyediting, typesetting, and review of the resulting proof before it is published in its final form. Please note that during the production process errors may be discovered which could affect the content, and all legal disclaimers that apply to the journal pertain. 


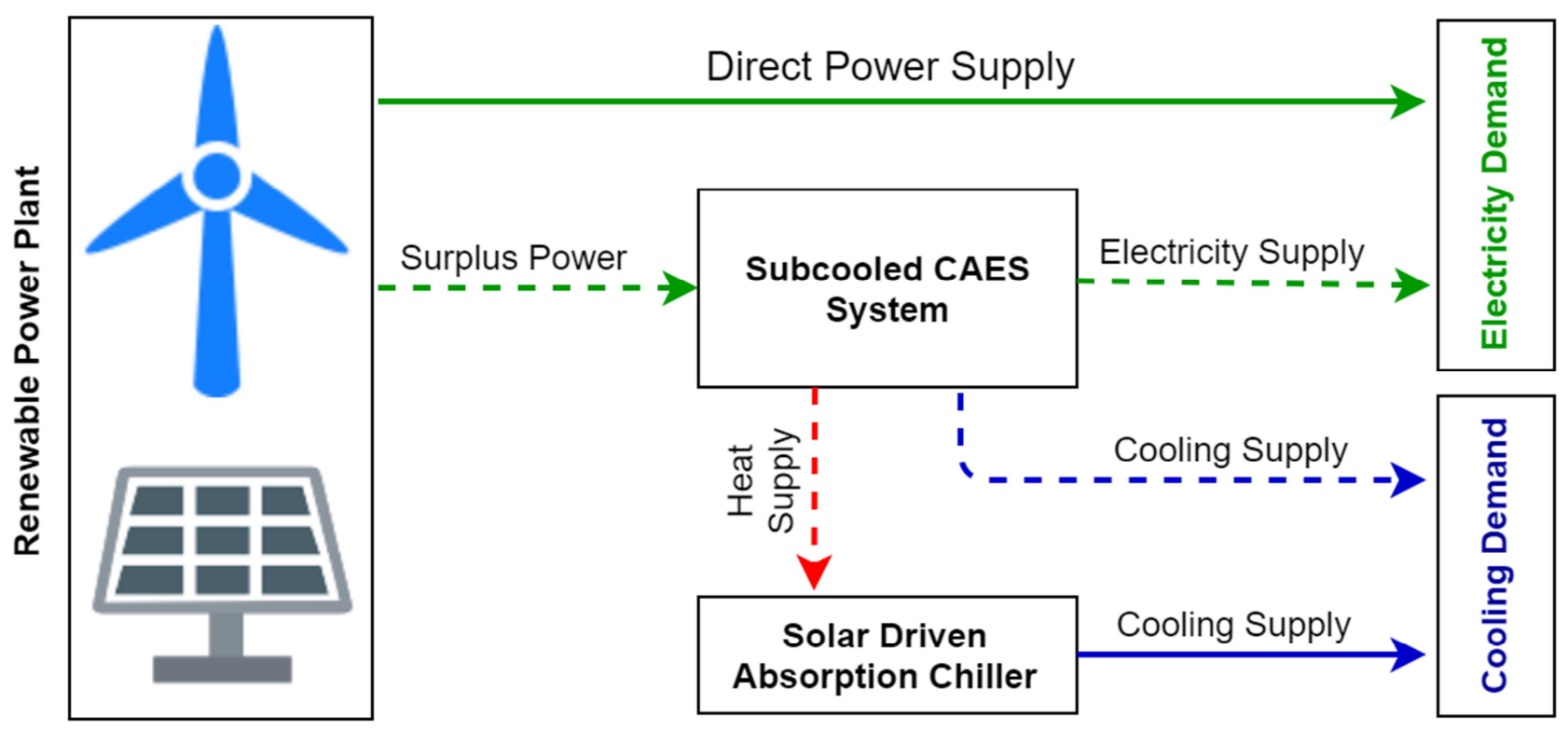




\title{
Design and Optimization of a Novel System for Trigeneration
}

\author{
A. Arabkoohsar*,a, G. B. Andresen ${ }^{\text {b }}$ \\ ${ }^{\text {a }}$ Department of Energy Technology, Aalborg University, Denmark \\ ${ }^{\mathrm{b}}$ Department of Engineering, Aarhus University, Denmark \\ *Corresponding Author: ahm@et.aau.dk
}

\begin{abstract}
Subcooled compressed air energy storage (SCAES) is a system cogenerating heat, cooling, and power at a high coefficient of performance. In this study, hybridization of a SCAES system with a large-scale solarpowered absorption chiller (SPAC) is proposed. The hybrid system sustainably provides cooling and power at high efficiency. The combined SPAC-SCAES system is appropriate for locations with large cooling demand and grid-connected renewable power plants. Employing this system, the renewable power plant may efficiently operate in the power market, maximizing the financial benefits by storing its surplus power and reclaiming the stored energy for balancing the demand and the production. In addition, a large amount of cold is produced, increasing the profitability of the system. This combined system is designed and simulated for a typical wind farm plus an absorption chiller of a hospital. Non-linear programming (NLP) is used to optimize the operation strategy of the SCAES and based on the given results; the components of the system are sized. The results show that by the combined system a massive amount of balancing power can be produced for the grid, a reliable integration between the cold and electricity sectors is made, and the levelized cost of energy (LCOE) decreases remarkably.
\end{abstract}

Keywords: Subcooled CAES, Solar-powered absorption chiller, Wind farm, Trigeneration, Non-linear programming. 


\section{Introduction}

Distributed energy systems including district heating and cooling networks are getting more popular worldwide [1]. These systems offer a sort of advantages compared to stand-alone energy production systems such as flexibility in building design and energy generation systems, lower costs, more efficient energy delivery processes and reduced carbon footprint [2]. Among distributed energy systems, electricity grids are widespread in most countries, district heating has received significant attention in some countries, and a less attention has been paid to district cooling. The main reason for this inattention may be due to the fact that the pioneers of district energy systems are the North-European countries where the demand for cooling is less than that felt for heating [3]. The trend has, however, changed over the last decades. As an example, district cooling covers well above $40 \%$ of Sweden's cold demand, today [4]. Although this value is only $4 \%$ for Denmark, the expansion of the areas covered by district cooling is of importance for the energy planners of the country [5].

In district cooling systems, the main energy supply technologies are generally large-scale compression and absorption chillers. As an absorption chiller is heat driven, it is most appropriate for district cooling applications where the main objective is the utilization of various waste heat sources in the network [6]. The research on the concept of absorption chillers began a long time ago and new studies bringing innovations in this field or proposing novel applications of this technology are still coming up every day. One of the most interesting schemes under development is the SPAC. In a SPAC, a considerable portion of the heating demand is supplied by solar energy. As the cooling demand is highly correlated with the solar irradiance, this concept results in impressive techno-economic outcomes. In one of the recent works in this area, Albers [7] increased the coefficient of performance of a SPAC and reduced its water consumption through an innovative design. In another work, concentrating Fresnel collectors were used for driving a set of absorption chillers. In this system, a high efficiency of around $60 \%$ was obtained for the solar thermal system and a favorable operation was observed from the chillers, demonstrating promising prospects for industrial process integration [8]. Marc et al. [9] dynamically modeled a medium-scale single effect solar assisted absorption chiller and validated their model with experimental results. Wang et al. [10] experimentally investigated the performance of solar assisted chiller co-fed with the waste heat from a gas engine. The coefficient of performance of this system reached 0.91 and 0.6 in waste heat mode and solar mode, respectively. Xu et al. [11] experimentally evaluated the performance of a variable effect absorption chiller designed for highly efficient solar cooling systems. Porumb et al. [12] investigated the operating conditions and performance of a SPAC, suitably describing the behavior of the equipment and precisely evaluating the safe operating conditions of the device. Bellos et al. [13] studied the dynamic energetic, exergetic and economic performances of a SPAC. Li et al. [14] carried out a thorough multi-objective optimization of SPAC machines for air-conditioning applications. In one of the most recent works in this area, Arabkoohsar and Andresen [15] proposed a dual-source absorption chiller driven by solar heat and district heating line for the 
large-scale cooling system of a hospital in Denmark. They observed a significant improvement in the performance of the conventional cooling system of the case study, a considerable saving in the consumption of the local district heating and a large emission reduction. In their next work, Arabkoohsar and Andresen [16] designed a hybrid solar assisted absorption chiller and a gas expansion station for the same case study to reduce the size of the cooling system and to take advantage of the free cooling and power production potential of the local gas station.

CAES technology is a promising electricity storage solution that has recently received much attention. The main reasons for such interest in this technology are the low capital cost, the high agility and the good energy conversion efficiency that the advanced configurations of the CAES offer [17]. The most advanced scheme of CAES so far has been multistage adiabatic CAES (ACAES) so-called isothermal ACAES (IACAES). This design of the technology presents a high round-trip efficiency of up to $80 \%$ [18]. The three other configurations of this technology are diabatic CAES (DCAES) [19], single stage ACAES [20] and lowtemperature ACAES [21]. A detailed explanation of the development stages of CAES technology and the features of each of the layouts may be found in [22]. In one of the latest works in this area, Arabkoohsar and Andresen [23] proposed an innovative design of CAES, cogenerating heat, cooling, and power, called SCAES. This system is, in fact, a further development of the IACAES design, aiming at producing cooling and power in the expansion stage as well as heat generation in the compression process. Although the powerto-power efficiency of this system is lower than the other schemes, the very high coefficient of performance of the system and the capability of Trigeneration of electricity, heat, and cold make this configuration a unique design and efficient techno-economically. The main restriction of this system is that its application is limited to locations with continuous heating and cooling demands.

In the present work, a hybridization of a SPAC and a SCAES system is proposed. By such a hybrid system, the storage system may provide all or a portion of the required heat of the chiller in the charging phase and a considerable portion of the cooling demand in the discharging mode. Therefore, the cooling duty of the chiller in the discharging mode of the storage unit decreases considerably. The heating demand of the absorption chiller in the discharging mode of the SCAES is provided by the solar thermal system to the possible extent. The remaining demand is provided by local district heating. In order to investigate the performance of the proposed system, it is designed, sized and analyzed thermodynamically for a case study in Denmark. The case study comprises a small part of a wind farm with an overall capacity of $300 \mathrm{MWp}$ and a hospital with a maximum annual cooling demand of 3.2 MW. The operation strategy of the energy storage is determined by employing NLP approach in MATLAB and then, based on the given results; the sizing of the components of the hybrid system is accomplished.

\section{Design of the SPAC-SCAES}




\subsection{The configuration}

The hybrid system is a combination of a SPAC and a SCAES unit. A very thorough explanation of these two technologies can be found in [15] and [23], respectively. Therefore, no configuration of these systems and only a short explanation about each of them is presented here.

In a SCAES unit, the system can be divided into two parts, i.e. compression and expansion. The compression part comprises a multistage compressor, intercooler heat exchangers, and an air reservoir. This part is active in the charging mode, increasing the pressure of the air reservoir and generating heat. In this phase, the compressors start working when surplus power is available. During the compression process, the airflow temperature increases, and the intercooling heat exchangers are used to withdraw this heat from the air stream. After exchanging heat with a working fluid, the compressed air is stored in the air reservoir. The expansion part includes a multistage single screw expander [24] with preheating heat exchangers before each stage, the air reservoir, and an electricity generator. This part is active in the discharging mode. In this mode, the compressed airflow is expanded and the electricity generator is actuated to generate electricity. Besides, as the airflow is expanded, its temperature falls and a considerable amount of cold is produced via the heat exchangers.

In a SPAC, a considerable portion of the required heat for driving the absorption chiller is supplied by a solar thermal unit. The rest of the heating demand is supplied via a secondary supplier, e.g. a fire-tube boiler, district heating, etc. A single effect LiBr-water absorption chiller is the suitable type of chiller for being powered by medium-temperature solar thermal systems [25]. In such solar systems, evacuated tube collectors are of the best choices.

Knowing the SPAC and the SCAES technologies, one may introduce the proposed hybrid SPAC-SCAES system. Fig. 1 presents a schematic diagram of this system. In this system, the energy storage part is to not only support a renewable power plant for storing its surplus power and providing dispatchable electricity to the grid but also to support the SPAC with its cold and heat production potential. The best operational strategy of the combined system depends on the availability of surplus power as described below:

a) The local renewable power plant, e.g. a wind farm, generates surplus power: In this case, the SCAES is in the charging mode. Therefore, no cooling is produced by the screw expanders. Instead, a large amount of heat is produced, which can be used to drive the chiller. The chiller receives this heat from the SCAES. As the temperature of the discharged water of the chiller generator is still at a very high temperature (around $85{ }^{\circ} \mathrm{C}$ ), it goes through the solar storage tank to heat it up to any possible temperature. As it will be explained later, the heat production of the system is more than its cooling generation. If the generated heat is more than the heat demand of the chiller, the surplus heat is stored for later use. This can be simply done using an insulated buffer tank with pressurized water as the heat storage medium. 
b) The wind farm demands auxiliary power: In this case, the storage unit goes to generation phase. In the generation phase, i.e. the discharge mode, no heat is generated by the SCAES. Instead, a large amount of cold is produced by the expansion devices. This cold stream is used to decrease the cooling duty of the chiller by direct supply of the district cooling. The chiller provides the rest of the cooling demand of the network and if the produced cold is higher than the instantaneous cooling demand, the surplus cold is stored. The cold storage can also be simply done via an insulated buffer tank with pressurized water as the storage medium. The solar thermal unit provides a considerable amount of heating for the chiller. If there is a need for additional heat, local district heating system may provide this. In addition to the produced cooling, a considerable amount of power is supplied to the electricity grid as well.

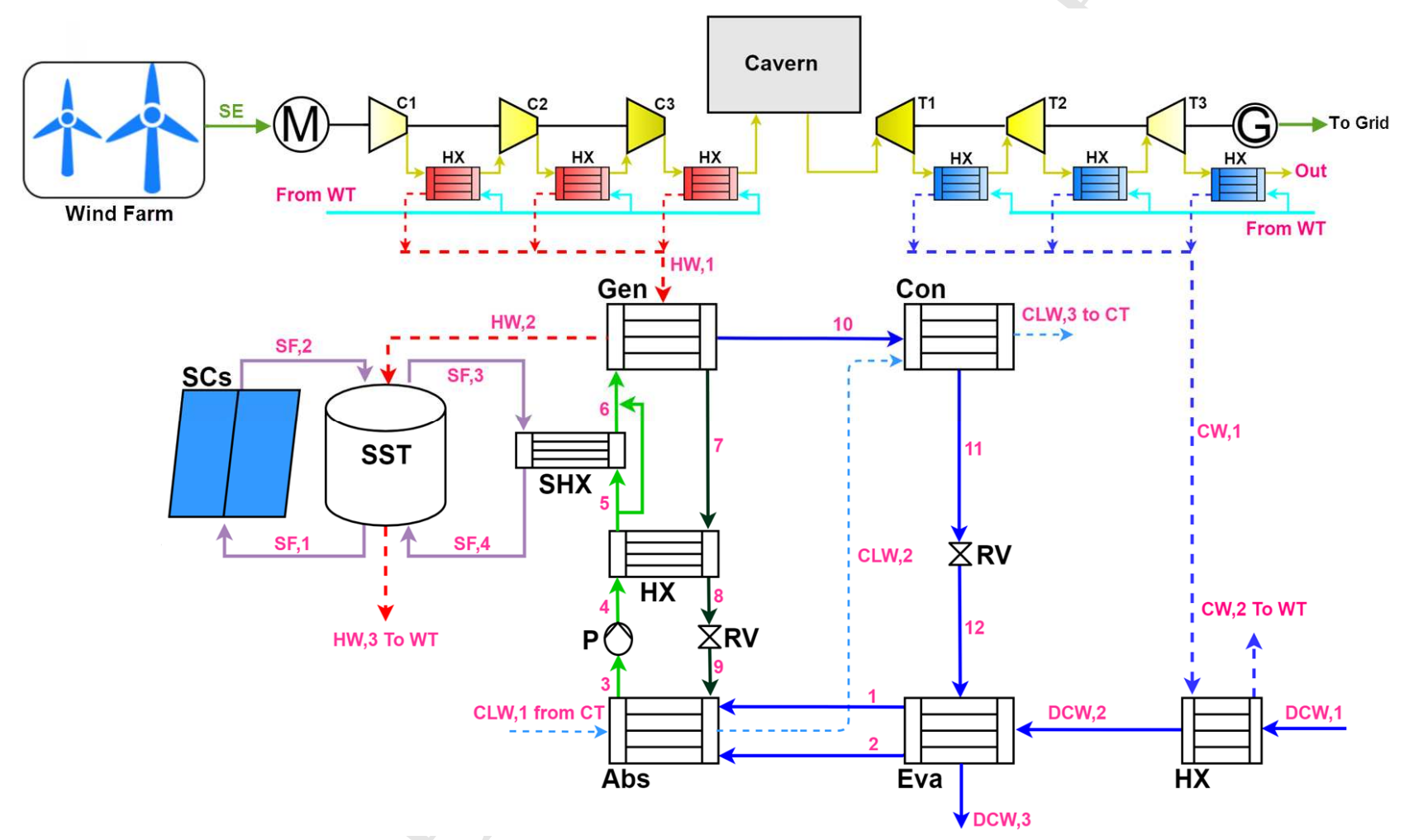

Fig. 1 Combined SPAC-SCAES system for the cogeneration of cooling and power, SE: surplus electricity, M: Motor, $\mathrm{C}$ : compressor, T: expander, HX: heat exchanger, G: electricity generator, HW: hot water, CW: cold water, yellow: compressed air, light blue: cooling/heating fluid in ambient temperature, dark blue: subcooled working fluid, red: hot working fluid, Abs: absorber, P: pump, RV: restrictor valve, HX: heat exchanger, SHX: solar heat exchanger, SST: solar storage tank, SCs: solar collectors, SF: solar system working fluid, Gen: chiller generator, Con: condenser, Eva: evaporator, CLW: cooling water, CT: cooling tower, DCW: district cooling water.

Note that the operational strategy and characteristics of the absorption chiller, such as temperatures, pressures, solution concentrations, etc. are similar to those used in Ref. [15]. The solar thermal features and the characteristics of the employed collectors are also the same as Ref. [15]. The SCAES characteristics, such as the pressures, pressure ratios, temperatures, etc. are adapted from Ref. [23]. 


\subsection{Sizing the hybrid system based on the case-specific conditions}

For accomplishing the simulation of the proposed hybrid technology, sizing of the main components and specification of the operational conditions of the system are necessary. Normally, the energy storage unit is sized considering the case-specific needs including the available surplus power, the local energy pricing strategies, etc. As such, the specific needs and considerations are effective for the absorption chiller. In this study, the cooling network of a hospital in Denmark is the case study. This hospital has a large district cooling network and takes advantage of a district heating connected absorption chiller to supply the required cooling. This system is not efficient enough during summer when the local district heating network works based on very low loads while the cooling demand is high. Consequently, the heat suppliers must work at higher loads to cover the chiller demand whereas the return water from the chiller is still at very high temperature, causing a large heat loss in the district heating pipeline. The detailed explanation of this problem and the solutions proposed are available in $[15,16]$. As the hybrid system in this work comprises an energy storage part, there should exist a renewable power plant with surplus power to feed the storage system. This is, in fact, a further reason for selecting this case study as the area has a large-scale wind farm suitable for this hybridization.

There are a number of important parameters required for sizing the system and simulating its performance for the case study. The first important parameter is the cooling demand of the local district cooling network. Fig. 2 shows the total daily cooling demand of the hospital [26]. According to the figure, even in the coldest months of the year, the hospital demands a base cooling load of $38 \mathrm{MWh} / \mathrm{day}$. The maximum total daily cooling of $77 \mathrm{MWh} /$ day is also required during the summer. The statistics show that a maximum of $3.2 \mathrm{MW}$ of cooling demand is recorded in the hospital during the hot summer days.

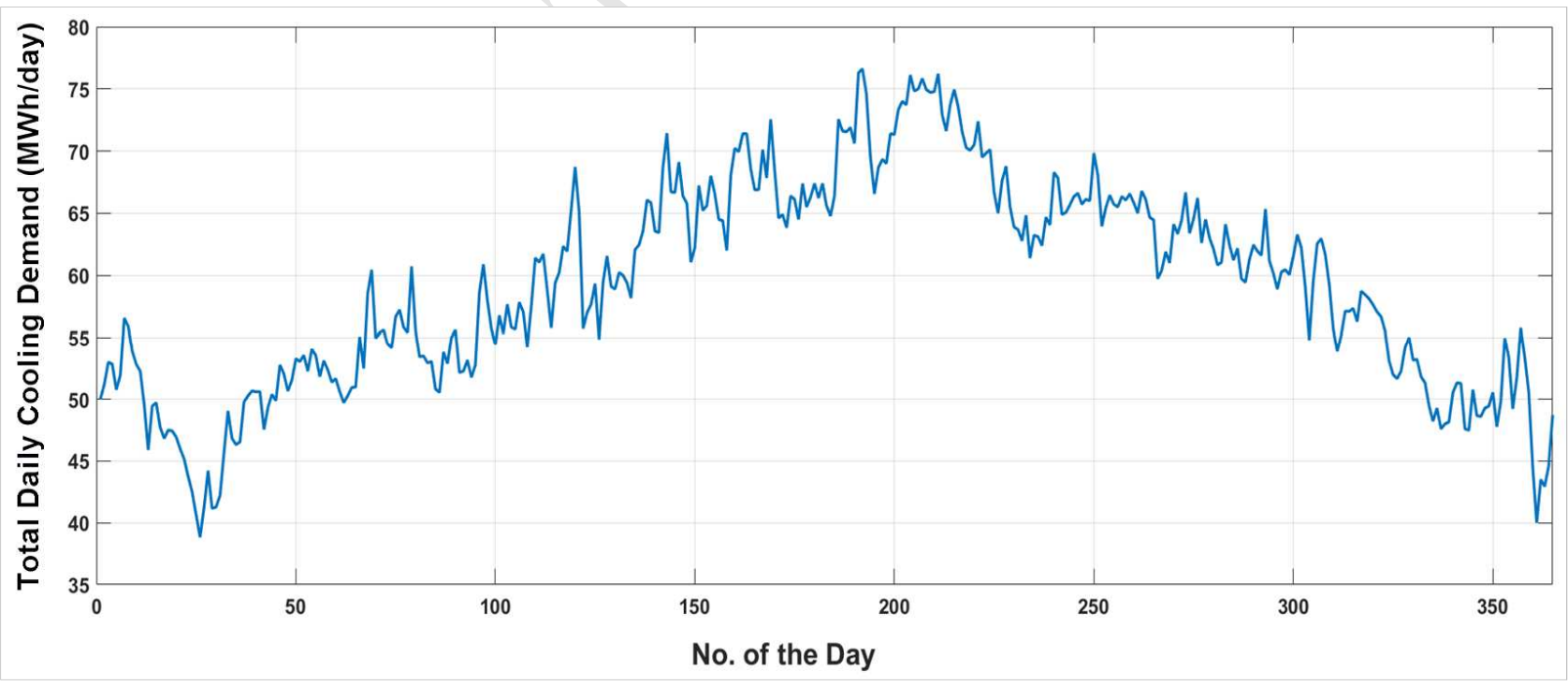

Fig. 2 Total daily cooling demand of the hospital during the year 2015 [26]. 
To better understand the effect of the conventional cooling system of the hospital on the local district heating network, one only needs to consider the total demand of the local district heating. Fig. 3 gives information about the total daily demand of Aarhus city district heating, where the hospital is located, before connection to the hospital chiller as well as the local waste incineration capacity during the year 2015 [27]. As seen, the heating demand of the whole city is slightly above $100 \mathrm{MWh} /$ day during summer. Taking into account the logical coefficient of performance of 0.7 for the chiller [9], and the maximum cooling demand of 77 $\mathrm{MWh} /$ day, the district heating system is imposed to a sharp extra load of around $110 \mathrm{MWh} / \mathrm{day}$. On the other hand, as seen, the waste incineration capacity, which is the primary source of district heating supply, is around $80 \mathrm{MWh}$ in this period. This means that for providing the requested heat of the cooling system of the hospital, the other heat plants of the network should come into operation.

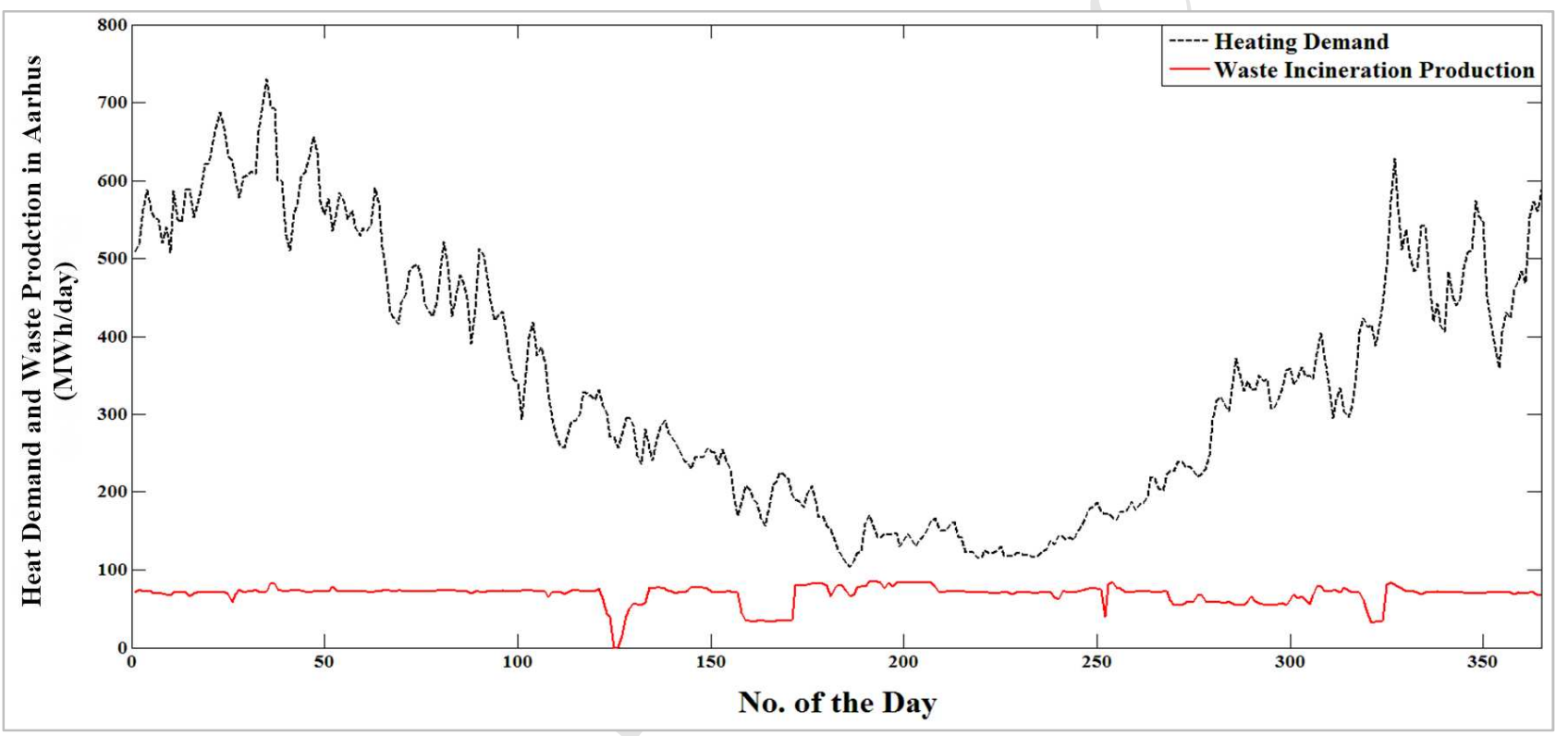

Fig. 3 Aarhus city district heating demand and waste incineration capacity in 2015 [27].

In addition, as the hybrid system includes a solar thermal system, the information about the local solar irradiance is a key piece of the required data for the project. The previous study of the authors indicates that the optimal slope angle in Aarhus is $45{ }^{\circ} \mathrm{C}$ [15]. The information about the theoretically and practically available irradiance on such a sloped surface in the case study is presented in [15]. According to the reference work, a maximum of almost $900 \mathrm{~W} / \mathrm{m}^{2}$ solar energy may irradiate theoretically at noontime during June-September while the practical peak value is below $800 \mathrm{~W} / \mathrm{m}^{2}$. In January, November, and December, the maximum practically solar radiation is below $200 \mathrm{~W} / \mathrm{m}^{2}$ [15].

The next important parameter is the operating strategy that the storage system works based on, i.e. the charging and discharging times and loads. This should indeed be defined through the energy market optimization of the wind farm coupled with a SCAES unit taking into account the electricity, cooling, and heating spot prices and the wind power availability. Here, this is carried out based on an NLP approach 
which maximizes the total annual achievable revenue from the SCAES system. The outcomes will be presented in the results section.

\section{Mathematical Modelling}

In this section, a detailed mathematical model of the system is presented comprising the thermodynamic model of the components, the optimization method, and the economic performance assessment criterion.

\subsection{Thermodynamic model of the system}

For presenting the thermodynamic model of the system, it is divided into two separate parts. First, the model of the SCAES is presented. For this part, depending on the operation mode, i.e. charging or discharging, different formulations are applied. In the charging phase, the index of power-to-heat efficiency is defined for the system as below:

$$
\eta_{p t h}=\sum_{t=1}^{t c}\left(\frac{\dot{Q}_{h}}{\dot{E}_{s}}\right)^{\lambda}
$$

where, $t c$ refers to the number of time steps in the charging mode, $\dot{Q}_{h}$ is the heat produced in this phase and $\dot{E}_{S}$ is the surplus power used by the SCAES to produce compressed air.

During discharging mode, as the system is bifunctional, two performance criteria are defined for the system. These criteria are power-to-cooling and power-to-power efficiencies as below respectively:

$$
\begin{gathered}
\eta_{p t c}=\frac{\sum_{t=1}^{t d} \dot{Q}_{c}^{\lambda}}{\sum_{t=1}^{t c} \dot{E}_{s}^{\lambda}} \\
\eta_{p t p}=\frac{\sum_{t=1}^{t d} \dot{E}_{d}^{\lambda}}{\sum_{t=1}^{t c} \dot{E}_{s}^{\lambda}}
\end{gathered}
$$

in which, $\dot{Q}_{c}^{\lambda}$ is the cooling production of the system and $\dot{E}_{d}$ is the power production of this system, $\mathrm{t}_{\mathrm{d}}$ is the number of time steps in the charging phase and $\lambda$ counts the operation time steps.

There is a detailed formulation of the SCAES system components in [23]. A brief mathematical model of these components is presented hereunder. For the compressor set, the total work available to drive the devices is the surplus power of the wind farm. Thus: 


$$
\dot{W}_{c}=\dot{E}_{s}=\sum_{j=1}^{n}\left(\dot{m}_{a} w_{c}\right)_{j}
$$

in which, $\dot{W}$ is the total work, $\dot{m}$ is mass flow rate, $w$ is the specific work of each compressor. The subscriptions $c$ and $a$ represent the compressor stages and the airflow, $n$ is the number of stages.

Similarly, the work production of the expanders is calculated by:

$$
\dot{W}_{t}=\frac{\dot{E}_{d}}{\eta_{g}}=\sum_{j=1}^{n}\left(\dot{m}_{a} w_{t}\right)_{j}
$$

where, $\eta_{g}$ is the electricity generator efficiency and the subscription $t$ stands for the expanders. The outlet temperature of the expanders and compressors are important parameters on the overall performance of the system and the following heat exchangers. Assuming adiabatic processes through each stage of the expanders and compressors, these items could be both calculated by:

$$
T_{e}=T_{i}\left(1+\frac{r^{\left(\frac{\mu-1}{\mu}\right)}-1}{\eta_{i s} \vartheta}\right)
$$

in which, $r$ refers to the pressure ratio and $\eta_{i s}$ is the isentropic efficiency of each of the devices. $\mu$ is the ratio of specific heat for air. The value of $\vartheta$ is 1 for the compressors and it is -1 for the expanders.

For the heat exchangers, considering counter-flow layout, based on $\varepsilon$-NTU method, one has:

$$
\begin{gathered}
T_{e, a}=T_{i, a}(1-\varepsilon)+\varepsilon T_{i, f} \\
\dot{m}_{f}=\frac{\dot{m}_{a} \overline{c_{p}}\left(T_{i, a}-T_{e, a}\right)}{c_{f}\left(T_{e, f}-T_{i, f}\right)}
\end{gathered}
$$

where, $\varepsilon$ is the effectiveness factor of the heat exchanger. The subscriptions $f$ refers to the secondary working fluid of the heat exchangers (water here). $\overline{c_{p}}$ is the airflow heat capacity and $c_{f}$ is the heat capacity of water.

Employing the formulation above, one can calculate the values of heat and cold production of the system through the heat exchangers as below:

$$
\dot{Q}=\sum_{j=1}^{n}\left(\dot{m}_{f} c_{f}\left(T_{e, f}-T_{i, f}\right)\right)_{j}
$$


With regard to the air reservoir, as it is assumed to be in temperature equilibrium with the environment, the only effective parameter is its pressure. For this term, one could write:

$$
P_{r}^{\lambda}=\left(\frac{m_{r} R T_{r}}{V_{r}}\right)^{\lambda} \quad \text { where: } m_{r}^{\lambda}=m_{r}^{\lambda-1} \pm \dot{m}_{a} \& T_{r}=T_{o}
$$

in which, $r$ refers to the reservoir and the superscription $m$ is the mass of air within the reservoir. Naturally, in charging mode, the mass of the air increases and it decreases in discharging mode. $\lambda$ is the time steps counter in this relation.

Finally, it is worth mentioning that in the formulation set presented above, the pressure ratio of the compressors is chosen as 5 , the expansion ratio of the turbines is 0.2 . While the isentropic efficiency of compressors is 0.85 , this parameter is no higher than 0.65 for the expanders [24]. The effectiveness factor of the heat exchangers is considered 0.8 .

The second part of this section is presenting the model of the SPAC. There are some assumptions and points regarding the absorption chiller that should be mentioned. Here, the heat losses from the heat exchangers and the piping are negligible, the refrigerant is pure water, the pressure is always constant but through the restrictors, there is only saturated liquid at points $2,3,7$ and 11 while there is saturated vapor at point 1 (refer to Fig. 1). Initially, one knows that the cooling duty of the chiller will decrease when the SCAES is in the discharging phase. In this case, one has:

$$
\dot{Q}_{e v}=\dot{Q}_{c d}-\dot{Q}_{c-s c a e s}
$$

where, $\dot{Q}_{c d}$ is the total cooling demand of the case study and $\dot{Q}_{c-s c a e s}$ is the cold provided by the SCAES unit. The SPAC should provide the rest of the demand. The energy balance of the evaporator can be written as follow:

$$
\begin{aligned}
& \dot{Q}_{e v}=\dot{m}_{12} h_{12}-\dot{m}_{1} h_{1}-\dot{m}_{2} h_{2}=\dot{m}_{d c w}\left(h_{d c w, i}-h_{d c w, e}\right) \\
& \text { where: } \dot{m}_{12}=\dot{m}_{1}+\dot{m}_{2}=1.025 \dot{m}_{2}
\end{aligned}
$$

in which, the subscription $d c w$ refers to the district cooling water stream. The inlet and outlet temperatures of this stream into and from the evaporator are $15{ }^{\circ} \mathrm{C}$ and $8{ }^{\circ} \mathrm{C}$, respectively. The energy balance of the absorber can be written as below:

$$
\dot{Q}_{a b s}=\dot{m}_{c l w}\left(h_{c l w, 1}-h_{c l w, 2}\right)=\dot{m}_{1} h_{1}+\dot{m}_{2} h_{2}+\dot{m}_{9} h_{9}-\dot{m}_{3} h_{3}
$$


where, $c l w, 1$ and $c l w, 2$ refer to the cooling water streams coming in and going out of the absorber. The physical properties of the absorber and the refrigerant in each point are based on those used and reported in [15]. The work of the pump is calculated by:

$$
\dot{W}_{p}=\dot{m}_{3} v_{3}\left(P_{3}-P_{4}\right)
$$

where, $v$ is the specific volume of the solution.

Writing the energy balance and mass conservation law of the solution heat exchanger as well as the restriction valve, one can proceed to model the solar heat exchanger and the supporting unit of it, i.e. solar thermal storage system. Regarding the solar storage tank, considering a stratified tank with $N$ nodes, the energy balance for each node can be written as below:

$$
T_{s t}^{\lambda+1, n}=T_{s t}^{\lambda, n}+\frac{\Delta t\left(\dot{Q}_{s s c}+\dot{Q}_{h w}+\dot{Q}_{m i x}-\dot{Q}_{s h x}-\dot{Q}_{l o s s}\right)^{\lambda, n}}{\left(m_{s t} c_{s f}\right)^{\lambda+1, n}}
$$

where, the superscript $n$ indicates the number of the node for which the energy balance is written and $s t$ refers to the storage tank. The parameters $\dot{Q}_{s s c}, \dot{Q}_{m i x}, \dot{Q}_{s h x}$ and $\dot{Q}_{l o s s}$ are respectively the heat supplied to the storage tank from the solar collectors, the heat transfer due to mass exchange between the nodes, the heat withdrawn from the storage tank for the solar heat exchanger and finally the rate of heat losses. These items are calculated by the following equations, respectively:

$$
\begin{aligned}
& \dot{Q}_{s s c}^{n}=F_{s f, 2}^{n} \dot{m}_{s f, 2}\left(T_{s f, 2}-T_{s t}^{n}\right) ; \quad \text { where: } F_{s f, 2}^{n}=\left\{\begin{array}{c}
1 \text { if } n=1 \& T_{s f, 2}>T_{s t}^{n} \\
1 \text { if } T_{s t}^{n-1} \geq T_{s f, 2}>T_{s t}^{n} \\
0 \quad \text { otherwise \& }
\end{array}\right. \\
& \dot{Q}_{s h x}^{n}=F_{s f, 4}^{n} \dot{m}_{s f, 4}\left(T_{s t}^{n}-T_{s f, 4}\right) ; \quad \text { where: } \quad F_{s f, 4}^{n}=\left\{\begin{array}{c}
1 \text { if } n=N \& T_{s f, 4}<T_{s t}^{n} \\
1 \text { if } T_{s t}^{n-1} \geq T_{s f, 4}>T_{s t}^{n} \\
0 \quad \text { otherwise }
\end{array}\right. \\
& \dot{Q}_{m i x}^{n}=\left\{\begin{array}{lll}
\dot{m}_{m i x}^{n}\left(T_{s t}^{n-1}-T_{s t}^{n}\right) & \text { if } & \dot{m}_{m i x}^{n}>0 \\
\dot{m}_{m i x}^{n+1}\left(T_{s t}^{n}-T_{s t}^{n+1}\right) & \text { if } & \dot{m}_{m i x}^{n+1}<0
\end{array}\right. \\
& \left\{\begin{array}{ccc}
0 & & \rightarrow
\end{array} \quad \text { if } n=1 \text { or } n=N+1\right. \\
& \text { where: } \dot{m}_{m i x}^{n}=\left\{\dot{m}_{s f, 2} \sum_{j=1}^{n-1} F_{s f, 2}^{n}-\dot{m}_{s f, 4} \sum_{j=1}^{n-1} F_{s f, 4}^{n} \quad \rightarrow \quad\right. \text { otherwise } \\
& \dot{Q}_{\text {loss }, n}=(U A)^{n}\left(T_{a}-T_{s t}^{n}\right)
\end{aligned}
$$


Also, the parameter $\dot{Q}_{h w}$ in Eq. 15 is the rate of heat supplied to each node by the hot water discharging from the generator via a hot helical coil through the storage tank. Dividing the coil length into $M$ nodes, one can write the energy balance for each node of the helical coil as:

$$
\rho c_{p} V \frac{\bar{T}_{h w}^{\lambda+1, m}-\bar{T}_{h w}^{\lambda}}{\Delta t}+\dot{m}_{h w} c_{p}\left(T_{h w}^{m+1}-T_{h w}^{m}\right)+(U A)_{h c}^{m}\left(\bar{T}_{h w}^{m}-T_{s t}^{m}\right)=0
$$

where: $\bar{T}_{h w}^{m}=\operatorname{mean}\left(T_{h w}^{m+1}, T_{h w}^{m}\right)$

in which, the subscript $h c$ refers to the helical coil, and the superscript $m$ is the number of node of the helical coil. $\rho$ is the density of the hot water, $V$ is the volume of water in each node and $\dot{m}$ is the mass flow rate of hot water. The overall heat transfer coefficient $(U A)$ is obtained from:

$$
(U A)_{h c}^{m}=\left[\frac{d_{h c, o}}{h_{i}^{m} d_{h c, i}}+\frac{r_{h c, o} \ln \left(\frac{r_{h c, o}}{r_{h c, i}}\right)}{k_{h c}}+\frac{1}{h_{o}^{m}}\right]^{-1} A_{h c, o}^{m}
$$

where, $d$ and $r$ are the diameter and radius of the helical coil, the subscripts $i$ and $o$ refer to the internal and external conditions and $A$ is the heat transfer area. Finally, one has:

$$
\dot{Q}_{h w}^{n}=\gamma \dot{Q}_{h c}^{m}=\gamma \sum(U A)_{h c}^{m}\left(\bar{T}_{h c}^{m}-T_{s t}^{n}\right)
$$

in which, $\gamma$ represents the number of $m$ nodes of the helical coil in each $n$ node of the storage tank. The heat supplied by the collectors may be calculated as below:

$$
\dot{Q}_{u}=A_{s s c}\left[S-U_{l}\left(T_{p}-T_{o}\right)\right]
$$

In this equation, $A_{s s c}$ is the collector module absorption area, $S$ is the absorbed solar flux, $U_{l}$ is the overall heat losses from the collectors and $T_{p}$ is the average temperature of the plate. The heat withdrawn from the storage tank to supply the absorption chiller, which is normally taken from the upper node, i.e. the hottest node, of the storage tank, is obtained from:

$$
\dot{Q}_{s h x}=\dot{Q}_{g}-\dot{Q}_{h-s c a e s}-\dot{Q}_{a u x}
$$


in which, $\dot{Q}_{g}$ is the total heat required in the generator of the chiller, $\dot{Q}_{h \text {-scaes }}$ is the heat provided by the

SCAES in the charging phase and $\dot{Q}_{a u x}$ is the auxiliary heat when the storage tank temperature falls below the required temperature. The minimum required temperature for driving the chiller of this study is $90{ }^{\circ} \mathrm{C}$.

For calculating the mass flow rate of the working fluid coming from the solar storage tank to the solar heat exchanger, one can write:

$$
\dot{Q}_{s h x}=\dot{m}_{s f} c_{s f}\left(T_{s f, 3}-T_{s f, 4}\right)=\dot{m}_{s} c_{s}\left(T_{6}-T_{5}\right)
$$

In this equation, the subscriptions $s$ refers to the absorption chiller solution (LiBr-water). The specific heat capacity of the solution in various ranges of concentrations can be calculated from the formulations given in [25].

The required heat in the generator equals the cooling demand divided by the coefficient of performance of the chiller $\left(\dot{Q}_{e v} / 0.7\right)$. The energy balance of the generator can be written as below:

$$
(\dot{m} h)_{h w, 1}+\dot{m}_{6} h_{6}=(\dot{m} h)_{h w, 2}+\dot{m}_{7} h_{7}+\dot{m}_{10} h_{10}
$$

It is also noteworthy that not all the heat gathered from the SCAES system in the charging phase of this system can be used directly for driving the chiller. In fact, as this heat is supplied in the form of a hot water stream, it is suitable for direct supply until its temperature is higher than $90{ }^{\circ} \mathrm{C}$. When the temperature falls below $90{ }^{\circ} \mathrm{C}$, it goes through the storage tank to charge it for higher possible temperatures (by means of the helical coil).

Finally, the energy balance of the condenser is also in the following form:

$$
\dot{m}_{c l w}\left(h_{c l w, 2}-h_{c l w, 3}\right)=\dot{m}_{11} h_{11}-\dot{m}_{10} h_{10}
$$

By employing the presented formulation and the relevant boundary conditions of each of the control volumes, one can simply accomplish the simulation of the hybrid SPAC-SCAES system.

\subsection{Optimization parameter}

The optimization part of this work includes two stages, i.e. the optimization of the operation strategy of the SCAES unit based on the electricity, heat and cooling spot prices as well as the wind power availability, and the optimal sizing of different components in the hybrid SPAC-SCAES system.

The optimal operating strategy of the SCAES unit is found based on the maximization of the benefit achievable from the system in the case study. For this, the total annual benefit function of the system which is defined as below should be maximized. 


$$
B F T_{\text {scaes }}=\sum_{t=1}^{t=8760}\left(\operatorname{prs}_{e l}^{t}\left(P_{\text {prod }}-P_{\text {cons }}\right)^{t}+\operatorname{prs}_{h}^{t} H_{\text {prod }}^{t}+\operatorname{prs}_{c}^{t} C_{\text {prod }}^{t}\right)
$$

where, prs is the spot price of electricity $(e l)$, heat $(h)$ and cooling $(c) . P, H$, and $C$ refer to power and heat and cold whereas the subscriptions prod, cons are respectively the production and consumption of the system. For this optimization process, the NLP method is used. The general form of an NLP problem is to minimize a scalar-valued function $f(x)$ of several variables $x$ subject to other constraints or functions that limit or define the values of the variables [28]. In mathematical form, this can be written as:

$$
\min f(x) \text { so that }\left\{\begin{array}{l}
c(x) \leq 0 \\
\text { ceq }(x)=0 \\
A . x \leq b \\
\text { Aeq. } x=b e q \\
l b \leq x \leq u b
\end{array}\right.
$$

where, $f(x)$ is the function that should be minimized, $c(x)$ and $c e q(x)$ are the nonlinear constraints of the function, $A, b, A e q$ and $b e q$ represent the linear constraints of the function and $l b$ and $u b$ are the lower and upper bounds of the variables in the function. For employing this approach in this work, the solver 'fmincon' in MATLAB was used.

Having the optimal operating strategy of the energy storage system, one knows with which rate the system can contribute to the cooling and heating production. This would help for sizing the three main components of the hybrid system. With regard to the chiller, the size is certain and equal to $3.2 \mathrm{MW}$ in nominal load. Thus, one should design/size a set of SCAES and a solar thermal unit that cost-effectively cover the absorption chiller demand.

- Regarding the energy storage unit, based on the design objectives, this unit is so sized that it produces all the heating demand of the chiller at maximum charging load. According to [23], the power-to-heat efficiency of the SCAES is $92 \%$. Thus, taking into account the coefficient of performance of the chiller (0.7), its maximum cooling duty through the whole year (3.2 MW) and an effectiveness factor of 0.85 for the heat exchanger delivering heat from the SCAES fluid to the generator of the chiller, the energy storage unit is sized as $5.5 \mathrm{MW}$ of charging capacity at nominal load. The nominal discharging load of the SCAES is also so sized that it produces the maximum cooling demand of case study. The ratio of the power-to-power and power-to-cold efficiencies of the SCAES has been reported as 31/32 [23]. Therefore, the discharging part of the SCAES is sized as 3.1 MW to cover a maximum cold demand of about 3.2 MW. Naturally, if there is any surplus heat produced by the SCAES in the charging mode or any surplus cold produced in the discharging mode, they are stored for later use when the demand goes higher. 
- A conventional method of sizing is also used for dimensioning the solar thermal system. Based on this method, the graph of the solar system cost and the graph of the annual operating cost of the system (here, the cost of heat bought from the district heating system) should be plotted on the same coordinate. The point at which these two graphs intersect represents the optimal size of the solar thermal system. A detailed explanation of this method of sizing may be found in [29]. In the results section, it will be discussed how a solar thermal unit with a total area of about $6800 \mathrm{~m}^{2}$ and a storage tank with $450 \mathrm{~m}^{3}$ is the most appropriate choice for this work.

\subsection{Levelized cost of energy (LCOE)}

The following relation shows how the LCOE of the combined system is calculated.

$$
L C O E=\frac{\sum_{y=1}^{Y}\left[\frac{\left(I C_{t}+M C_{t}+O C_{t}\right)}{(1+r)^{y}}\right]_{y}}{\sum_{y=1}^{Y}\left[\frac{\left(C P+E P \times \frac{X_{e}}{X_{c}}\right)}{(1+r)^{y}}\right]_{y}} ; \text { Where }:\left\{\begin{array}{l}
I C_{t}=I C_{a c}+I C_{s c a e s}+I C_{s s} \\
M C_{t}=M C_{a c}+M C_{s c a e s}+M C_{s s} \\
O C_{t}=E C_{s c a e s}+H C_{a c}
\end{array}\right.
$$

In this equation, $I C$ is the initial cost of the equipment including the installation costs, $M C$ is the maintenance costs and $O C$ is the operation cost of each component. $r$ is the interest rate, $y$ refers to the number of the year and $Y$ is the useful lifetime of the system. The item $E C$ is the annual cost of the electricity used to charge the SCAES system and $H C$ is the annual cost of heat bought from local district heating to drive the absorption chiller (in case auxiliary heat is required). The subscripts $a c$, scaes and $s s$ are respectively the absorption chiller, the SCAES unit, and the solar thermal system. Clearly, the initial cost of the systems is only for the first year and it is zero for the next years. The annual operation and maintenance cost is considered equal to $3 \%$ of the capital cost of the system. On the other hand, in the denominator of the equation, $C P$ and $E P$ are the total annual cooling and electricity production in MWh. The ratio of the annual average power and cooling production prices $\left(X_{e}\right.$ and $X_{c}$ ) is used to convert the power production of the system into economically equivalent cooling production.

For calculating the LCOE of the SCAES and the combined absorption chiller-SCAES without the solar thermal system, Eq. 30 can be used provided that the irrelevant parameters (i.e. solar system capital cost and its operating and maintenance costs) are removed from the relation.

Due to the restriction in having access to the realistic costs of the components at various capacities and models, the mean value of the very different prices given in the literature/market was used for each of these facilities. In addition, in order to be conservative in the calculations, a relatively high installation and running cost of $20 \%$ of the capital cost was considered for the involved equipment. Table 1 presents information about the economic values needed for calculating the LCOE of the system. 
Table 1. The economic values required for calculating the value of LCOE.

\begin{tabular}{|c|c|c|}
\hline Parameter & Value & Reference \\
\hline Absorption chiller cost $(€ / \mathrm{kW})$ & 300 & {$[30,31]$} \\
\hline Solar thermal system cost $\left(€ / \mathrm{m}^{2}\right.$ of the collector) & 85 & {$[32,33]$} \\
\hline SCAES cost $(€ / \mathrm{kW})$ & 1000 & {$[34,35]$} \\
\hline Installation and running cost (\% of the IC) & 20 & {$[35]$} \\
\hline Operation and maintenance cost (\% of the IC) & 3 & [18] \\
\hline Interest rate $(\%)$ & 4 & [24] \\
\hline The useful lifetime of the assets (years) & 20 & [23] \\
\hline Mean annual electricity generation price (€/MWh) & 30 & {$[23]$} \\
\hline Mean annual heat production price ( $€ / \mathrm{MWh})$ & 21 & [23] \\
\hline Mean annual cooling production price (€/MWh) & 28 & [23] \\
\hline
\end{tabular}

\section{Simulation results and discussions}

The results of the simulations and optimizations carried out on the proposed combined cooling and power production system based on the realistic dynamic operation of the case study are presented in this section.

Fig. 4 shows the profiles of the spot price of heat and electricity that are required in the simulation and optimization processes. This information is associated with the production prices. In Denmark, there is a big difference between the production price and the fee that the energy consumers pay, which is mainly due to the tax regulation of the country. Unfortunately, there is no information about consumption prices. For this system, one only needs the heat consumption cost of the absorption chiller when fed by the local district heating system. As the chiller demands high-temperature heat, this makes a large relative heat loss in the district heating system during the warm months. During the colder months, it is relatively lower. Having said this, just as an approximation, a factor of 2 is taken into account for heat consumption cost ( 2 times of the production price).

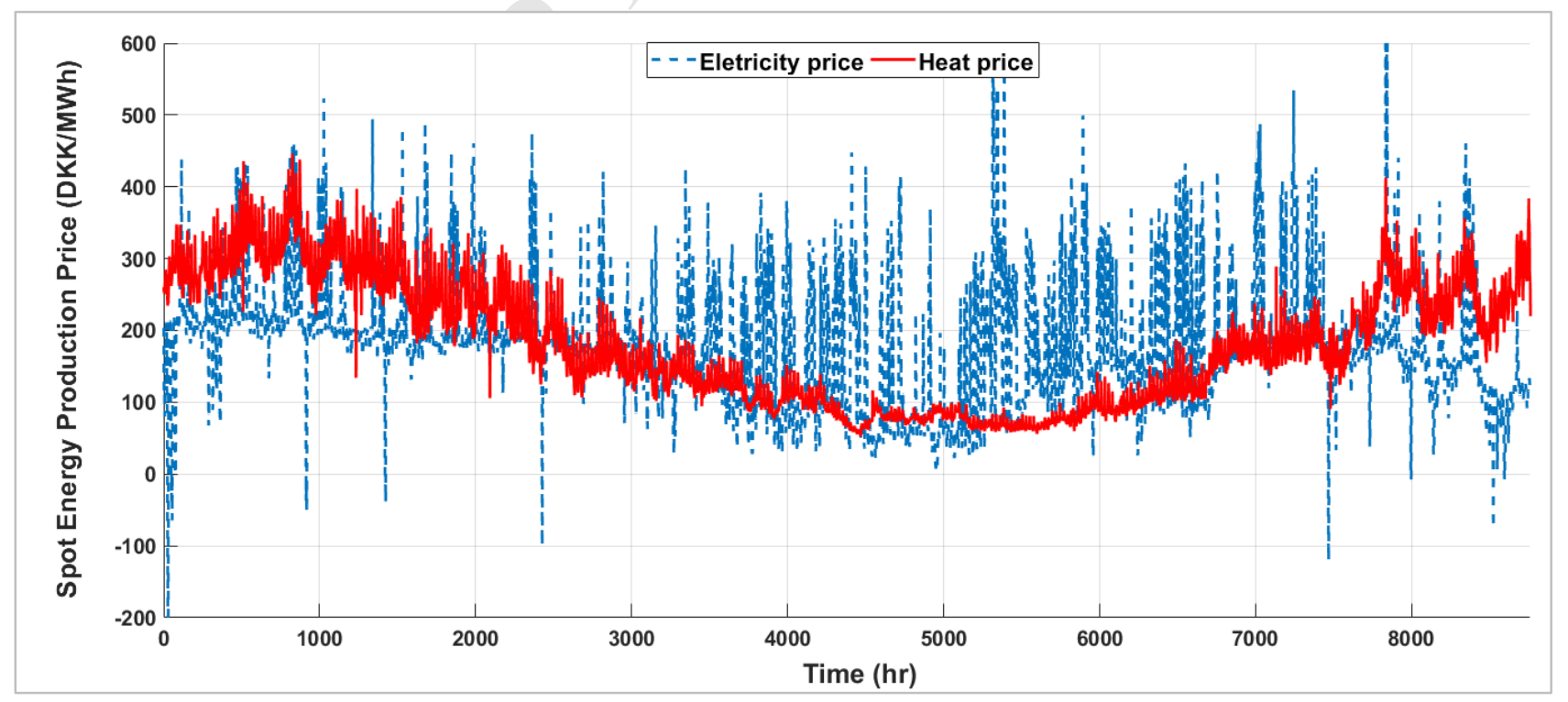

Fig. 4 Heat and electricity spot prices in the western Denmark market over an entire year. 
Generally, electricity is more valuable than heat. However, as can be seen from the figure, the high share of wind turbines has caused the electricity spot price to fall significantly and even to negative values sometimes. This is mainly why, during some periods of the year, it is seen that heat is more expensive than electricity. As another possible reason, one could refer to the too high load of district heating system (due to either too low ambient temperature or due to one of the heat production plants running out of function for any reason) for which the expensive auxiliary heat reserves must come into operation. Fig. 5 shows the heat price profile versus the ambient temperature and demand of the network in a daily averaged format to show how the heat production price varies as a function of these two factors. Expectedly, as the temperature comes down, the heat price goes up and the bigger demand values are corresponding with the more expensive heat production.

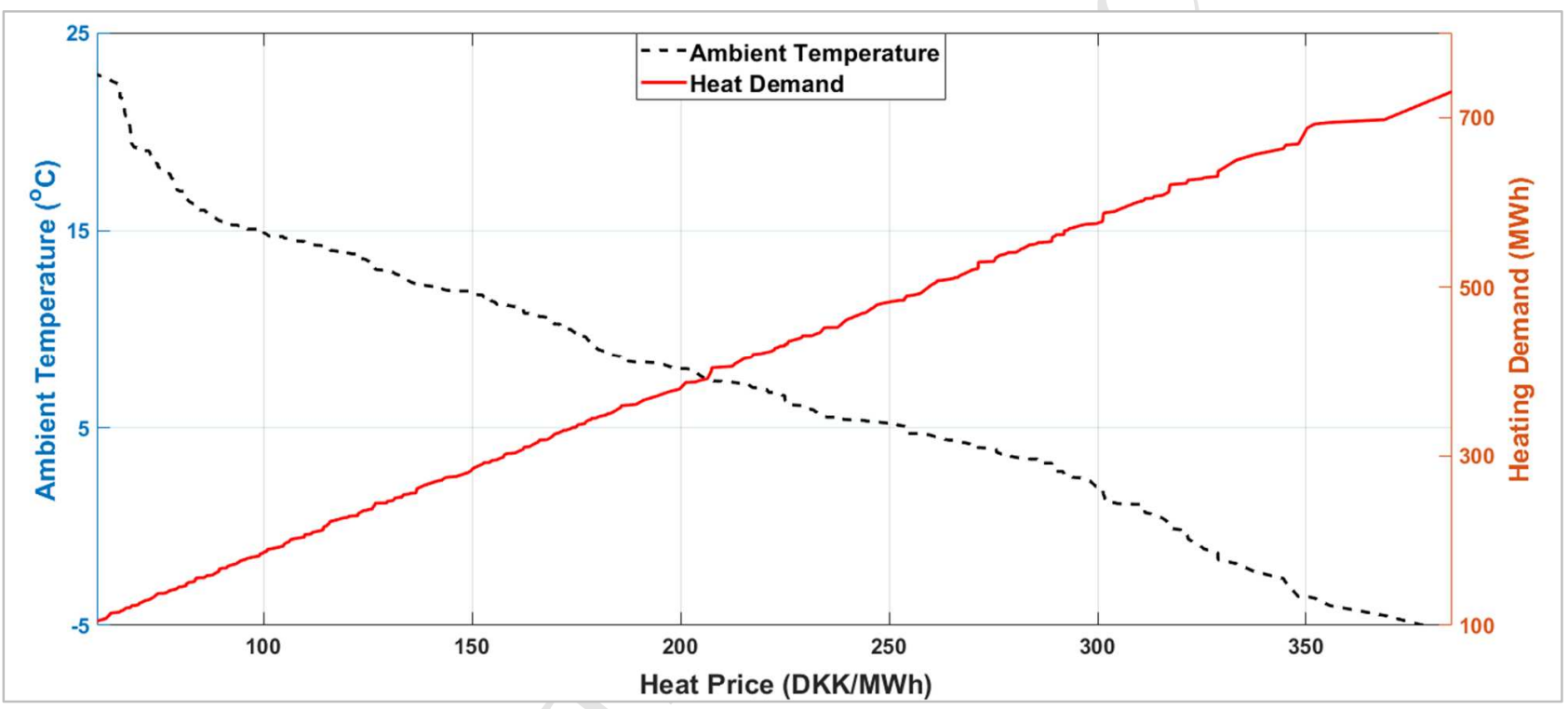

Fig. 5 Heat demand and ambient temperature versus heat price over one sample year of heat market in Aarhus.

Fig. 6 illustrates the results of the NLP optimization on the optimal operation strategy of the SCAES system, with a maximum capacity of 5.5 MW in charging and 3.1 MW in discharging, along with the electricity spot price over the first 100-hour period of the year. According to the figure, when the electricity price is low the system starts charging and in contrast, it starts discharging when the spot price goes up. This reveals that the optimization tool has performed very well. Note that the figure is presented based on the hourly average charging and discharging rates while the optimization process output is based on 5-min time scales. 


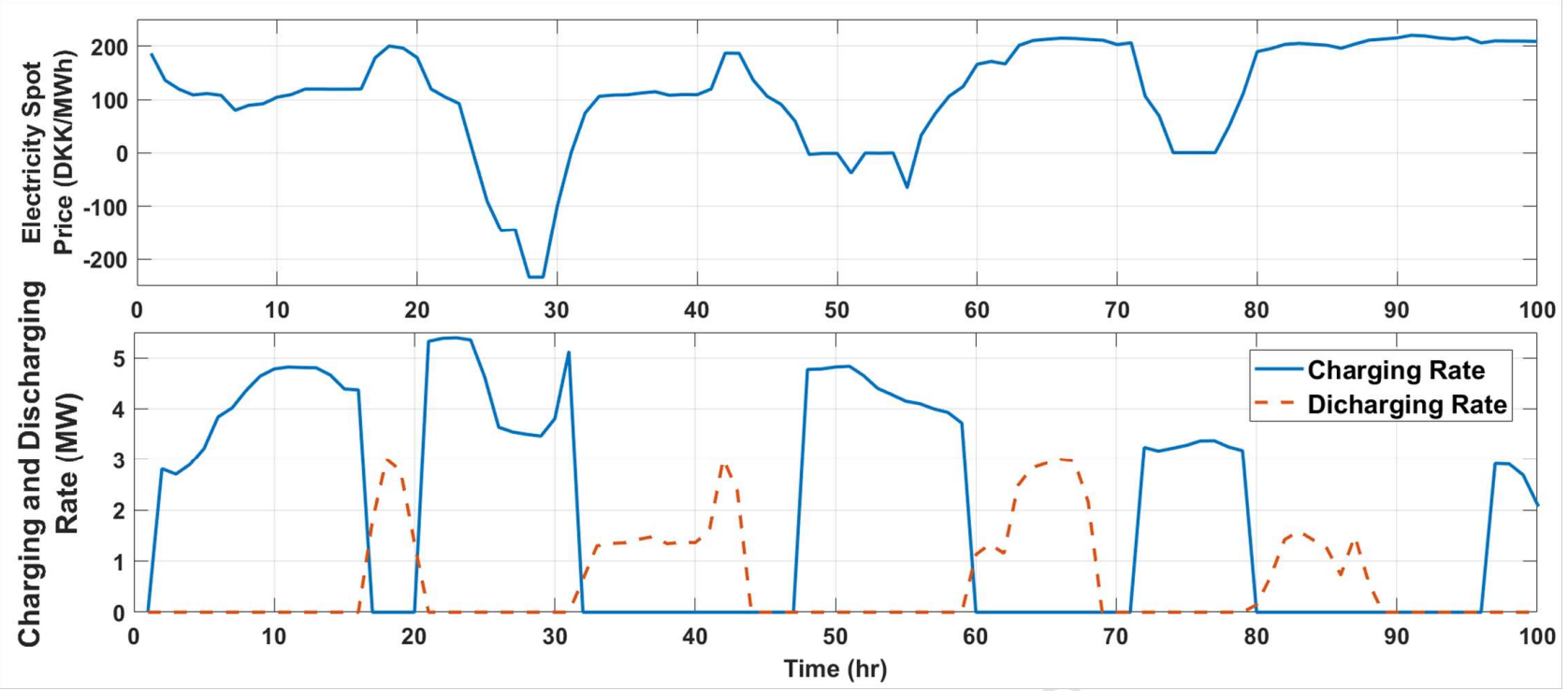

Fig. 6 Optimal operation strategy of a SCAES system in the case study.

Fig. 7 illustrates the duration curve of the SCAES power consumption and heat production in charging mode together with the power and cooling production rate in discharging mode. As seen, the system is in the charging mode over a majority of the time (about 72,000 5-min time steps which is about $68 \%$ of the whole year) while it has been producing cold and power during the rest of the time. The maximum charging rate is 5.5 MW while the maximum production rate in the discharging mode is about 3.1 MW. The total annual power used by the compressors in the charging phase is about $11.4 \mathrm{GWh}$ and the total annual power produced in the discharging mode is approximately $5.2 \mathrm{GWh}$. It means that an extremely interesting overall power-to-power efficiency of about $46 \%$ is achieved by the system, which is $15 \%$ higher than the previously reported efficiency value for the SCAES in [23]. This is to some extent a further effect of the optimal operating strategy found for the system, but more effectively, the consequence of an increased minimum pressure value for the cavern (2.5 MPa in this work). The power-to-cold efficiency of the SCAES in this system is about $47.5 \%$ and therefore, the cold to power output ratio of 32/31 is achieved again, resulting in a maximum cooling production rate of $3.2 \mathrm{MW}$. The rate of power-to-heat efficiency in this system is $92 \%$, which is the same as the value reported in [23]. 


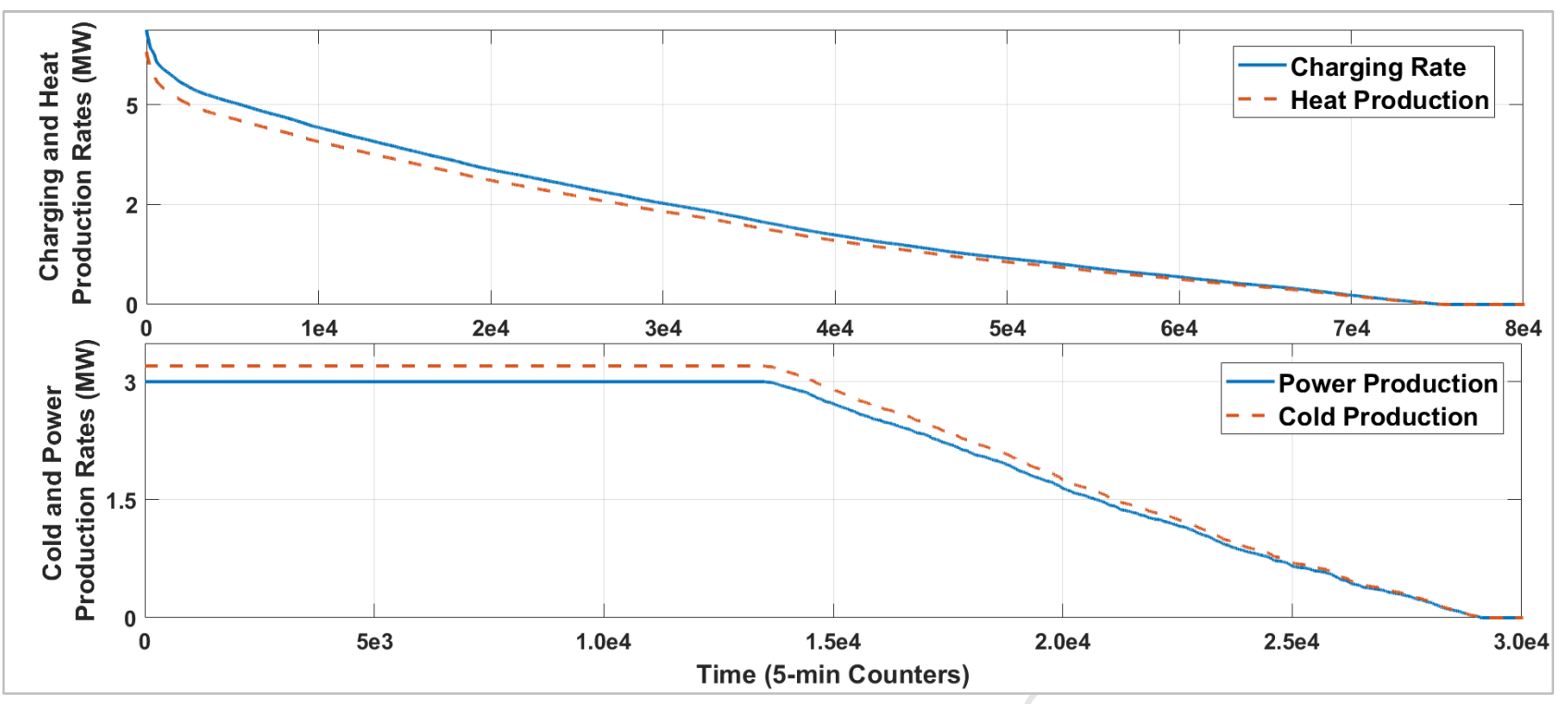

Fig. 7 Duration curve of the SCAES system performance in charging and discharging modes.

Naturally, by such dynamic operation of the SCAES unit, the cavern pressure fluctuates sharply. Fig. 8 shows how the cavern pressure varies over time during the year. According to the figure, the cavern pressure varies between a maximum of $12.5 \mathrm{MPa}$ and a minimum value of $2.5 \mathrm{MPa}$. It is underlined that the constraint of the minimum cavern pressure of $2.5 \mathrm{MPa}$ has been considered in the optimal operating strategy determination to keep the cavern structure safe from collapsing due to the high pressure of the surrounding material underground. The cavern volume for this specific SCAES unit is $10,000 \mathrm{~m}^{3}$.

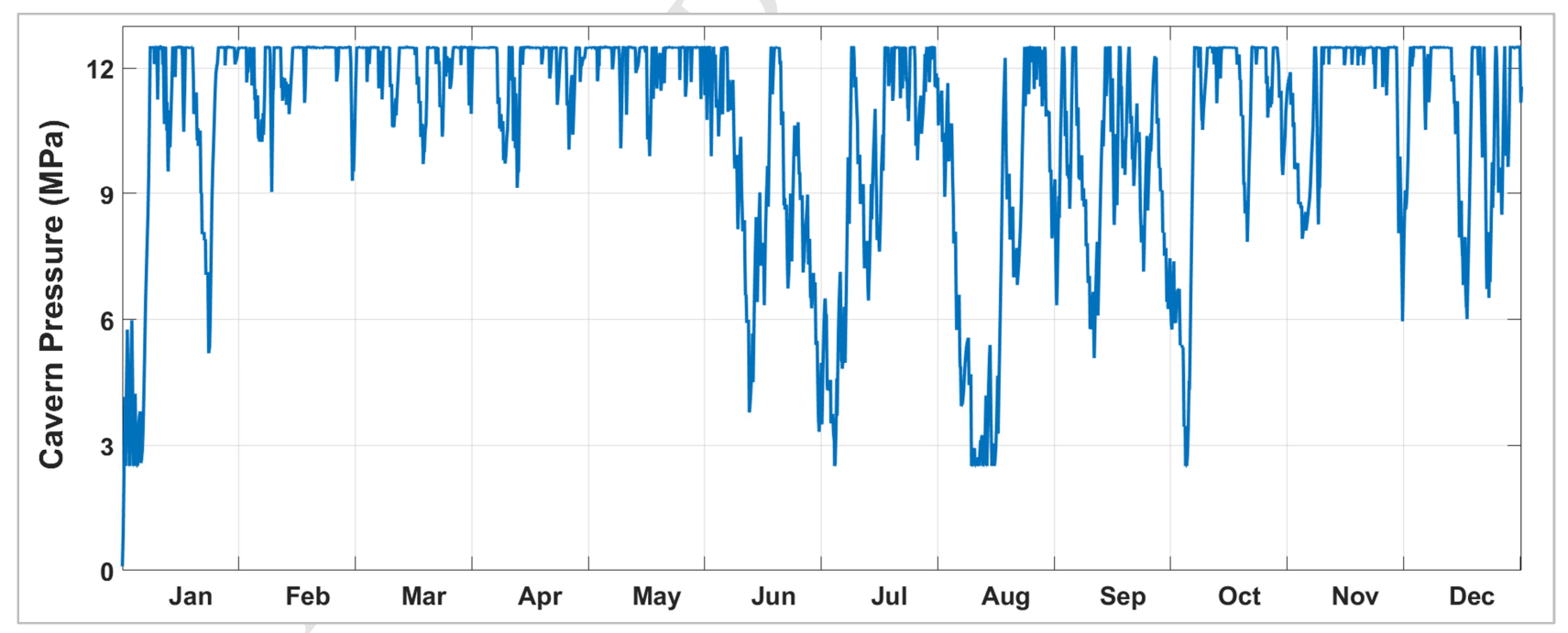

Fig. 8 The cavern pressure fluctuation over time

Fig. 9 shows the duration profiles of the cooling duty of the chiller in the conventional configuration and after being connected to the SCAES system. In this figure, the area below the black solid line represents the demand of the hospital, which must be covered by the absorption chiller in the conventional configuration, and the area below the blue dashed line is the amount of cooling that the chiller should cover after being 
connected to the SCAES unit. In other words, the area between these two graphs is the amount of cooling provided by the SCAES unit, i.e. the saving offered by the hybridization process in the cold production process. According to the data associated with this figure, a total of $4.4 \mathrm{GWh}$ is effectively (taking the losses through the heat exchangers and the storage units) is supplied by the SCAES unit. This is about $20 \%$ of the total annual demand of the hospital.

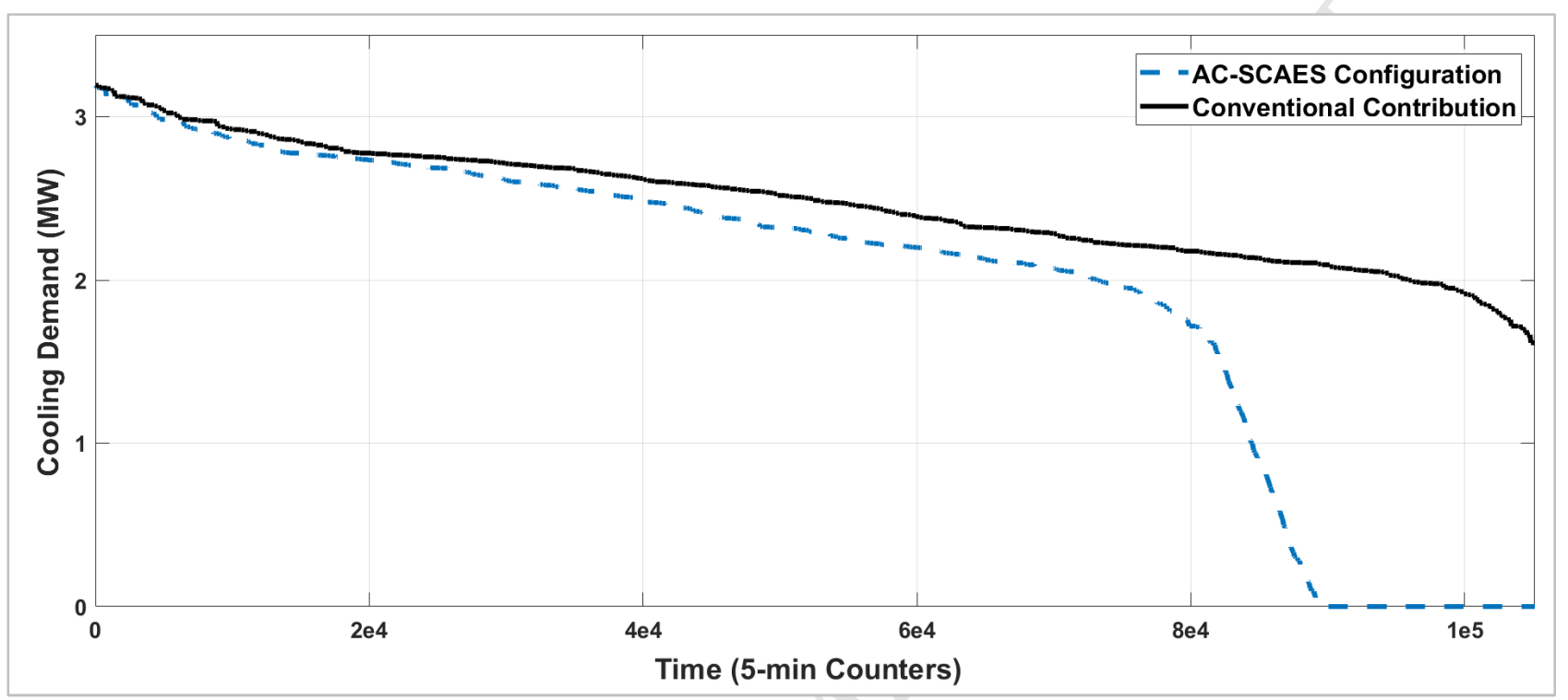

Fig. 9 Cooling demand of the hospital and the SCAES unit contribution in cold production.

In a similar manner as the previous figure, Fig. 10 gives information about the heating demand of the chiller before and after connection to the SCAES unit. The area between the two curves represents the amount of saving offered by the hybrid system in the heat demand of the chiller. As seen, the heat supply contribution of the SCAES is considerably higher than its cooling coverage contribution. This is, in fact, because of three main reasons: i) the cooling duty of the chiller is already reduced due to the contribution of the SCAES in cold production, resulting in lower heat demand of the chiller, ii) higher charging capacity of the SCAES relative to its discharging rate, and iii) the higher power-to-heat efficiency of the SCAES compared to its power-to-cold efficiency (almost double). According to the data of this figure, the high total annual heat demand of the chiller in the conventional configuration $(\sim 31 \mathrm{GWh})$ is reduced to only $15.8 \mathrm{GWh}$ due to the SCAES unit heat and cold supply contribution, that is about $49 \%$ reduction in the heat demand of the chiller. 


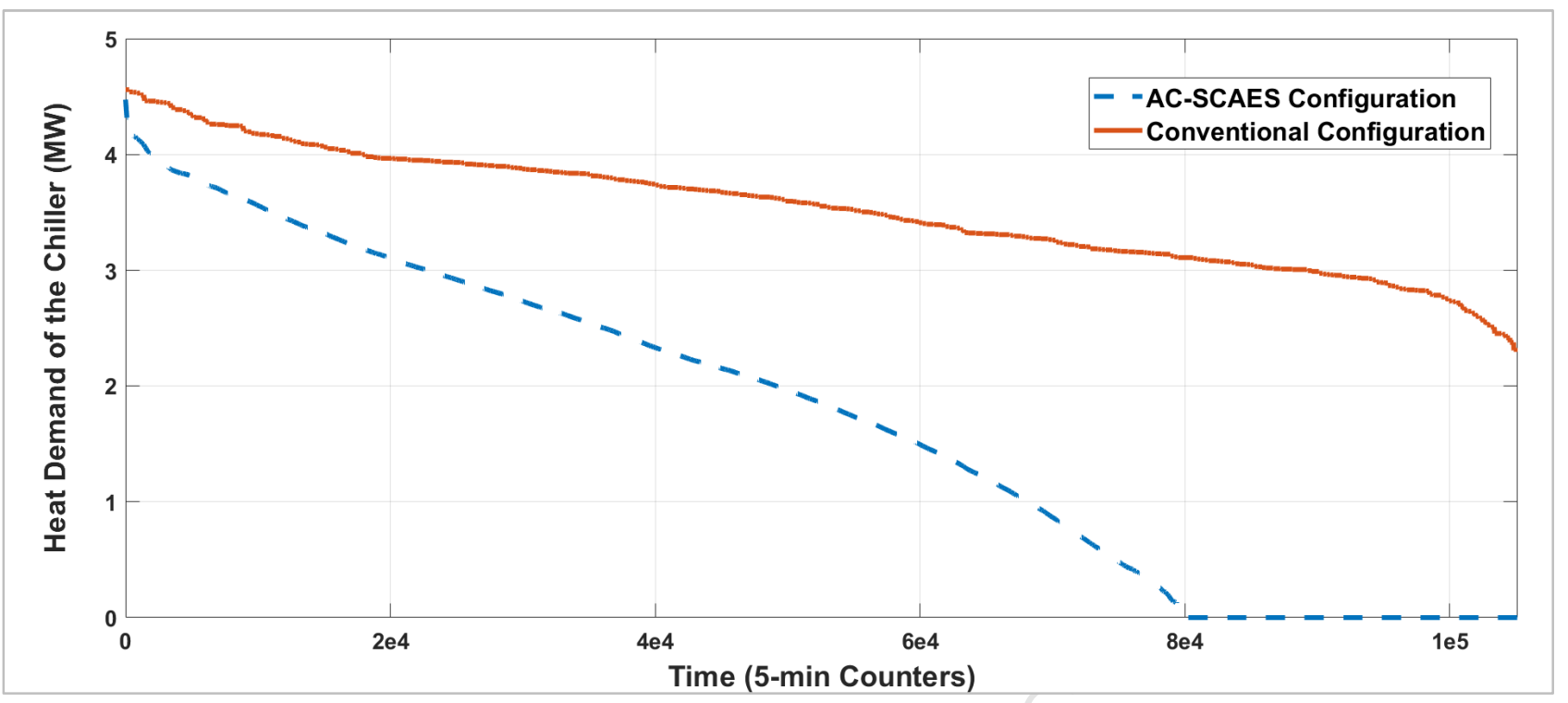

Fig. 10 Heating demand of the chiller before and after combination with the SCAES unit.

Fig. 11 presents a comparison between the total daily heat demand of the AC-SCAES and conventional chiller configurations. As the figure shows, although a remarkable annual deduction in the heat demand of the chiller is made, the heating duty reduction over some days in the summer is not significant. This is due to the lower wind power availability during the hot summer days. This is why employing an accessory solar thermal system would much help for the summer, when the solar energy is also more available. According to Fig. 11, a maximum daily heat demand of about $98 \mathrm{MWh} /$ day remains in the combined AC-SCAES system. One way for dimensioning the solar system is to so size the solar system that it covers all the remaining demand of the cooling system. However, taking into account the limited intensity of solar irradiation in Denmark as a northern country, a super large solar system would be required which is not economically feasible. An alternative method for sizing the solar system is considering the cost of the solar system and the cost that we would be subjected to if the solar unit was not be employed (i.e. fee paid to the district heating system). The size of the solar unit at which these two costs are equal represents a rational dimension for the system. A detailed explanation of this sizing method is available in [36]. Calculations show that a solar thermal system with about $6800 \mathrm{~m}^{2}$ evacuated tube collectors and a solar storage tank with $450 \mathrm{~m}^{3}$ is the best choice for the case study. 


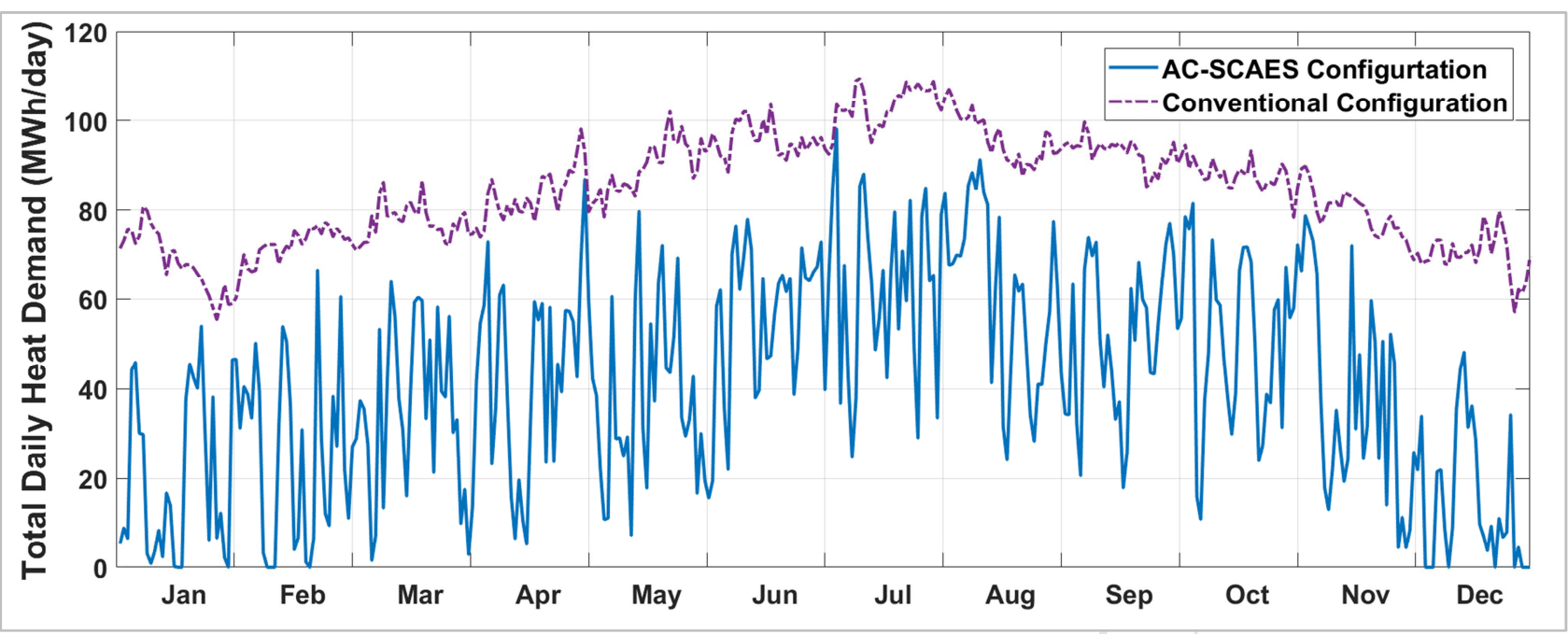

Fig. 11 Total daily heating demand of the chiller before and after combination with the SCAES unit.

Fig. 12 shows the amount of solar energy successfully injected into the chiller, reducing the heating demand of the hybrid system. This figure presents data in 5-minute time steps. As seen, the contribution of the solar system in heat production of the hybrid system is extremely higher in the summer compared to its contribution during the colder months, where it is practically zero. This is in practice expectable in Denmark, whereas for southern countries, not only the solar system performance during the summer can be better, its winter contribution can also be significantly higher.

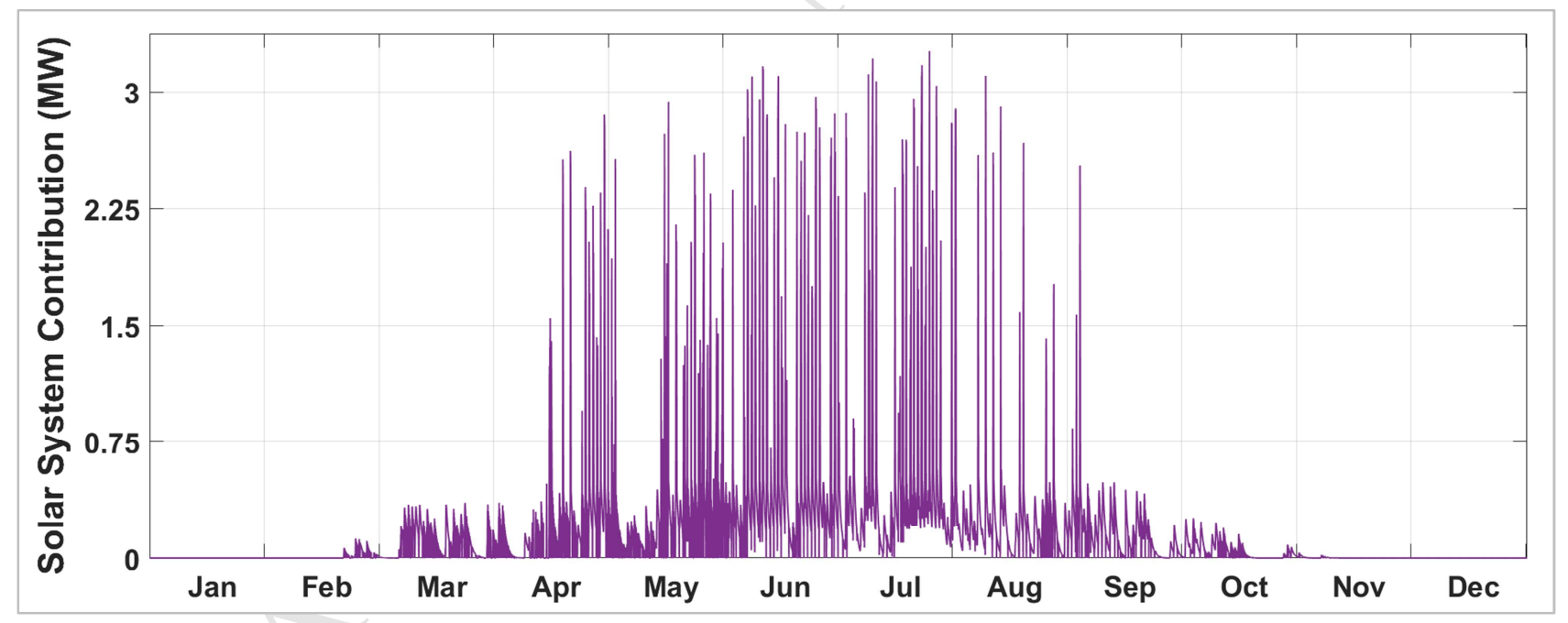

Fig. 12 Solar system contribution in heat production for the cooling system

Having the hybrid system optimally operating and optimally sized, one can see how much the share of each of the SCAES unit, the solar unit, and the district heating system are in heat preparation for the chiller. Fig. 13 shows the values of hourly averaged heat demand of the chiller in the conventional configuration, after connection to the SCAES system (the AC-SCAES), and in the SPAC-SCAES configuration. According to the figure, the heat demand of the SPAC-SCAES is significantly lower than the conventional chiller and 
even, considerably lower than the AC-SCAES configuration. This means that a huge saving has been achieved in the heating duty of the district heating system, especially during the critical operating time of summer.

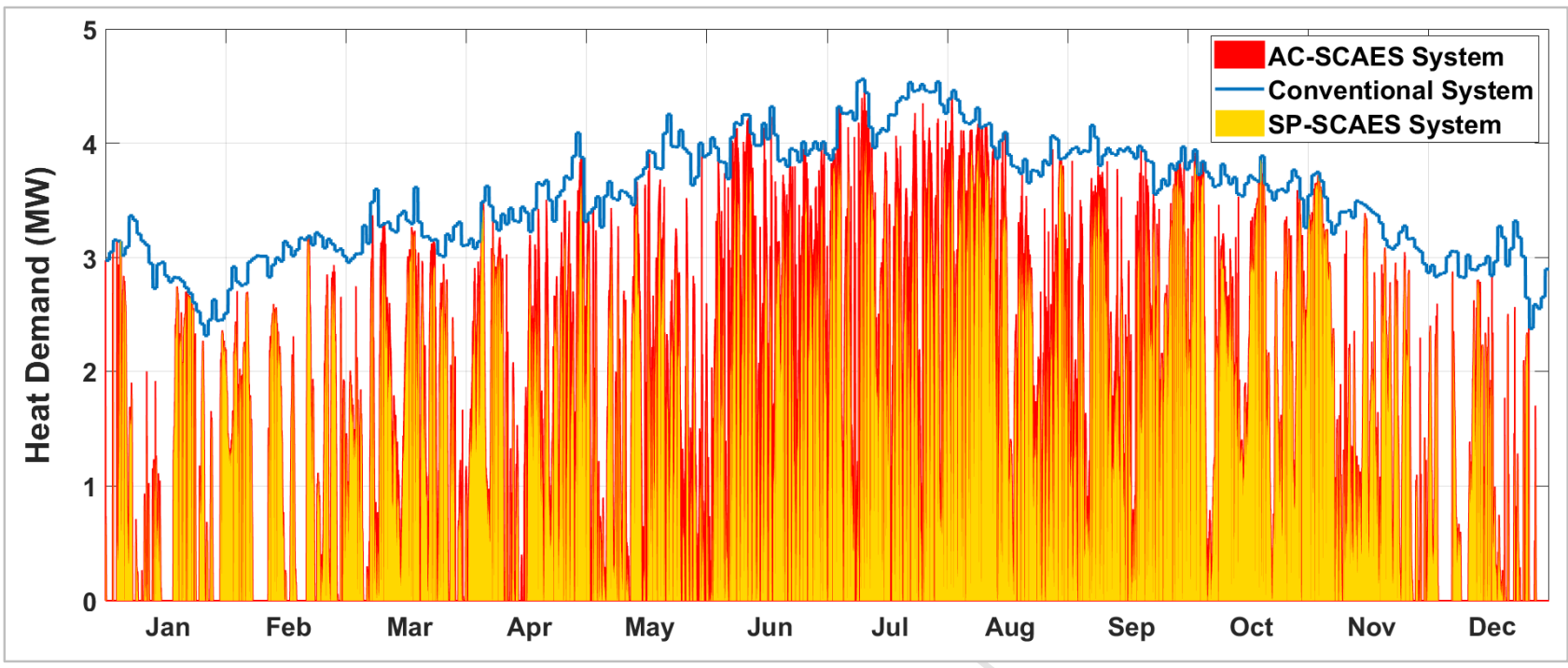

Fig. 13 Hourly averaged heating demand of the AC, AC-SCAES and ACSP-SCAES configurations.

Table 2 presents information and statistics about the total annual contribution of different systems on cold, heat and power productions in the combined configuration. According to the figure, the SCAES reduces the cooling demand by $24.6 \%$. The remained cooling demand is covered by the absorption chiller. Out of the 23.3 GWh heat required to drive the absorption chiller at this stage, about $49 \%$ is covered by the SCAES unit and only $42.9 \%$ is taken over by the district heating system.

Table 2. Statistics of the hybrid system for the cooling production and heating preparation

\begin{tabular}{|c|c|}
\hline Parameter & Information \\
\hline Annual cooling demand of the conventional system $(\mathrm{GWh})$ & 21.6 \\
\hline Annual heating demand in the conventional system $(\mathrm{GWh})$ & 30.9 \\
\hline Annual cold production of the SCAES in the AC-SCAES (GWh) & 5.3 \\
\hline Annual heat production of the SCAES in the AC-SCAES (GWh) & 11.4 \\
\hline Annual heating demand in the AC-SCAES $(\mathrm{GWh})$ & 23.3 \\
\hline Annual DH heating duty in the AC-SCAES (GWh) & 11.9 \\
\hline Annual solar system contribution in the SPAC-SCAES (GWh) & 1.5 \\
\hline Annual heating duty of DH system in the SPAC-SCAES (GWh) & 10.4 \\
\hline SCAES cold production contribution in the SPAC-SCAES $(\%)$ & 24.5 \\
\hline SCAES heat production contribution in the SPAC-SCAES $(\%)$ & 50.2 \\
\hline Solar thermal system contribution in the SPAC-SCAES $(\%)$ & 6.2 \\
\hline DH system contribution in the SPAC-SCAES $(\%)$ & 44.6 \\
\hline
\end{tabular}

There are two important notes regarding the solar thermal system. The first fact is that the number $6.2 \%$ refers to its contribution out of the total demand of the SPAC-SCAES system, and its contribution for district heating dependence reduction is $1.45 \mathrm{GWh}$ out of $11.9 \mathrm{GWh}$, i.e. about $12 \%$. The second fact is that even though $12 \%$ does not seem like a big share, this service is very valuable as it is given during the critical period of summer. 
In addition, one should note that in the simulation of various cases, the electricity consumption of the absorption chiller is considered negligible. Generally, for a single effect LiBr-Water absorption machine, there are three main sources of electricity consumption, namely the refrigerant pump, the solution pump, and the cooling tower pump. The electricity consumption of the refrigerant pump and the solution pumps are respectively less than $0.05 \%$ and $0.25 \%$ of the cooling capacity the absorption chiller. The required electricity of the cooling tower will be about $2 \%$ of the cooling capacity [37]. For example, for the conventional absorption machine of the hospital with a peak cooling capacity of $3.2 \mathrm{MW}$, in nominal capacity operation, the refrigerant and solution pumps consume $1.6 \mathrm{~kW}$ and $8 \mathrm{~kW}$ while the cooling tower electricity use will be $65 \mathrm{~kW}$. These three altogether will consume $74.6 \mathrm{~kW}$ electricity which is only around $2.3 \%$ of the cold production capacity of the chiller.

Fig. 14 shows the value of the LCOE of the five different cases, namely, the conventional chiller, the SCAES system, the solar system alone, the combined AC-SCAES and the hybrid SPAC-SCAES system.

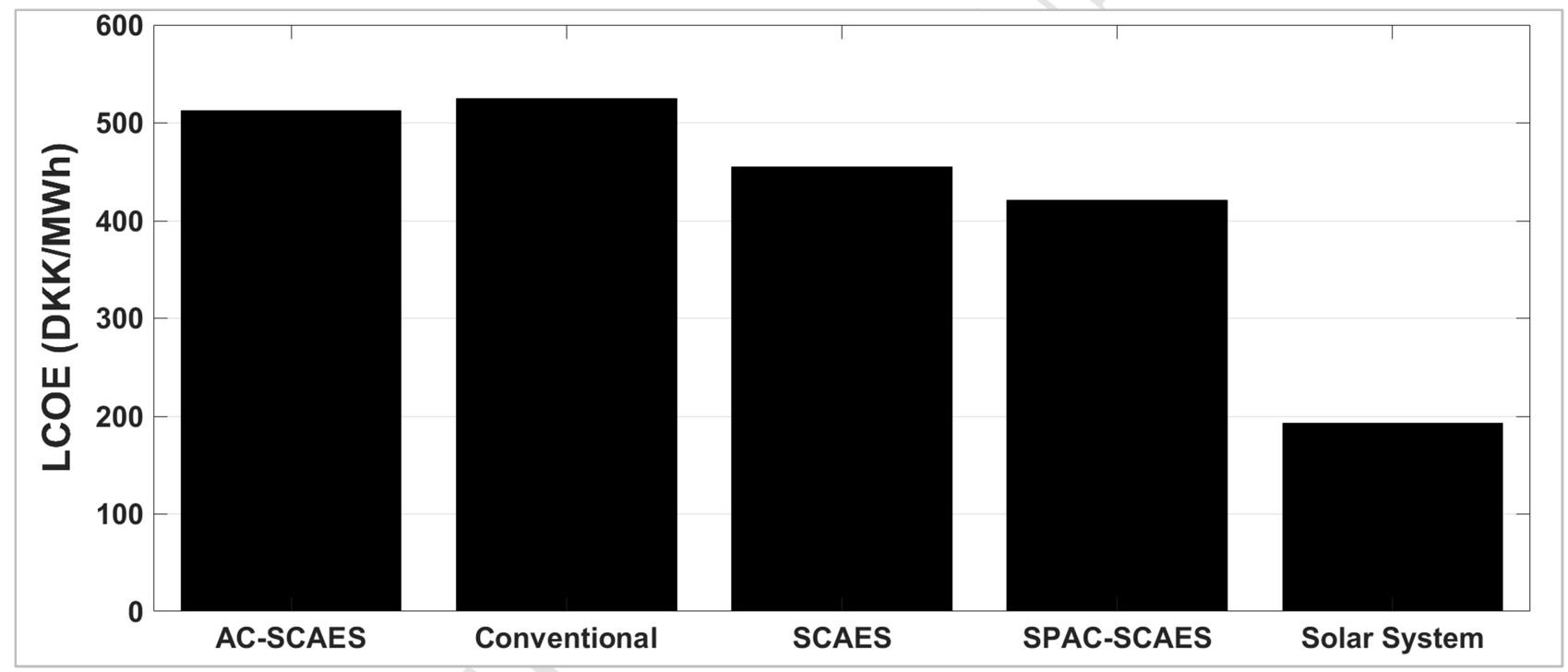

Fig. 14 Comparison of the LCOE value of the system in the different configurations.

As seen, the conventional system, i.e. the absorption chiller, offers a high LCOE of about $525 \mathrm{DKK} / \mathrm{MWh}$ (70 €/MWh). On the other hand, the solar thermal system offers the very interesting LCOE of 195 DKK/MWh (26 €/MWh), even though Denmark is not very rich in terms of solar irradiation. This is mainly due to the subsidies that the government pays for renewable energy, keeping the cost of the system low.

The next important point is that the SCAES system presents a low LCOE (455 DKK/MWh $=60.7 € / M W h)$. The main reason for this is that this system offers a very high coefficient of performance (about 1.85 based on the configuration and operating strategy defined in this work). According to the figure, the combination of the absorption chiller and the SCAES unit (AC-SCAES) results in a very interesting LCOE of 510 $\mathrm{DKK} / \mathrm{MWh}(76 € / \mathrm{MWh})$ and this is due to the cost-effective contribution of the SCAES and proper sizing of this system for the case study. And not surprisingly, the LCOE of the SPAC-SCAES system is even more 
desirable, equal to $420 \mathrm{DKK} / \mathrm{MWh}$ (56 €/MWh), indicating the important role of the solar thermal system not only on the technical aspects but also on the economic performance of the system.

In the end, it should be noted that the correction factor considered for the heat consumption price (i.e. 2) does not change the operation methodology of the system in any way. Indeed, the only effect of a different correction factor is on the results of the optimization algorithm that finds a different charging/discharging plan for the SCAES unit and consequently changes the economic outcome of the conventional and new systems accordingly. Naturally, the larger heat consumption price, the higher operation cost of the absorption chiller as it is supplied by district heating only. This will slightly increase the operation cost of the hybrid system as well because the hybrid SPAC-SCAES system is partially supplied by district heating. Therefore, the obtained LCOE for the conventional system will be dramatically larger while the LCOE of the SPACSCAES system will be slightly higher. This means a larger saving and a stronger proof of the costeffectiveness of the proposed system. In contrast, if a smaller correction factor is chosen, the costeffectiveness of the proposed system will be less impressive. A correction factor below 2 does not make sense because a major portion of the energy cost in Denmark is related to the taxes, distribution costs, etc.

\section{Conclusion}

The SCAES is a recently introduced energy storage technology, which produces heat, cooling and electricity in a cost-effective manner and at a high overall coefficient of performance. In this work, an innovative configuration was proposed through which the SCAES is combined with a large-scale SPAC to decrease the cooling duty and the LCOE of the chiller. On the other hand, if a large scale absorption chiller is supplied by district heating system, the critical problem would be the too much heat demand of the chiller during summer when there is not enough heat in the district heating. The other big advantage of the hybrid SPAC-SCAES system is overcoming this challenge and minimizing the dependency of the cooling system on the district heating grid.

In order to prove the sufficiency of the proposal, the hybrid system was designed; sized and analyzed for a large-scale absorption chiller in Denmark where the share of wind power is dramatically high and therefore, the existence of an energy storage unit would make a great sense. The challenge of the energy storage system was determining an optimal operating strategy due to a large number of effective parameters on the optimal techno-economic performance of the setup. Naturally, professional optimization methods are required for this, however, the NLP approach, which is precise enough and acceptable to a very good extent, was used in this work. Employing the results of this optimization, one could size the SCAES unit and subsequently, the solar thermal system.

The results show that the hybrid system LCOE is much lower than the conventional system and the problem 
of dependence on district heating during summer time is totally resolved. In addition, the unit can play an active role in the power market, mainly as an emergency production unit. For this, the very low startup time of the system is a big advantage, enabling the unit to come into operation on the scale of seconds. Considering the results obtained from the simulations for the case study, it could be concluded that the proposed hybrid technology can be reliably used for supplying cold and electricity, especially where there is a renewable power plant (e.g. wind farm or a solar power plant), and consequently, there is a need for an electricity storage unit. The proposed hybrid system might be considered as an active element of the future energy systems, in which a high share of renewable energy is expected, there must be concrete integration and synergies between various energy systems, and district cooling and heating networks are widely distributed.

As a future work on this topic, a professional optimization algorithm that can optimize the performance of the whole combined SPAC-SCAES system, not the energy storage unit only, is proposed. In addition, the observations showed that the wind power availability is low during summer when a more active operation of the SCAES would result in a bigger contribution to the cold production. Therefore, the hybridization of an absorption chiller with a SCAES unit coupled with a PV system, for instance, would result in a significant improvement in the performance of the hybrid SPAC-SCAES system. This configuration will also be designed and investigated as a future work in this context.

\section{References}

1. Jin Hou, Peng Xu, Xing Lu, Zhihong Pang, Yiyi Chu, Gongsheng Huang, Implementation of expansion planning in existing district energy system: A case study in China, Applied Energy, Volume 211, 1 February 2018, Pages 269-281.

2. Henrik Lund, Neven Duic, Poul Alberg Østergaard, Brian Vad Mathiesen, Smart energy systems and 4th generation district heating, Energy, Volume 110, 1 September 2016, Pages 1-4.

3. Wenjie Gang, Shengwei Wang, Diance Gao, Fu Xiao, Performance assessment of district cooling systems for a new development district at planning stage, Applied Energy, Volume 140, 15 February 2015, Pages 33-43.

4. Jenny Palm, Sara Gustafsson, Barriers to and enablers of district cooling expansion in Sweden, Journal of Cleaner Production, Volume 172, 20 January 2018, Pages 39-45.

5. https://stateofgreen.com/en/sectors/heating-and-cooling

6. Karolina Petela, Giampaolo Manfrida, Andrzej Szlek, Advantages of variable driving temperature in solar absorption chiller, Renewable Energy, Volume 114, Part B, December 2017, Pages 716-724.

7. Jan Albers, New absorption chiller and control strategy for the solar assisted cooling system at the German federal environment agency, International Journal of Refrigeration, Volume 39, March 2014, 
Pages 48-56.

8. Christine Weber, Michael Berger, Florian Mehling, Alexander Heinrich, Tomas Núñez, Solar cooling with water-ammonia absorption chillers and concentrating solar collector - Operational experience, International Journal of Refrigeration, Volume 39, March 2014, Pages 57-76.

9. Olivier Marc, Frantz Sinama, Jean-Philippe Praene, Franck Lucas, Jean Castaing-Lasvignottes, Dynamic modeling and experimental validation elements of a $30 \mathrm{~kW} \mathrm{LiBr} / \mathrm{H} 2 \mathrm{O}$ single effect absorption chiller for solar application, Applied Thermal Engineering, Volume 90, 5 November 2015, Pages 980-993.

10. Jialong Wang, Jingyin Wu, Hongbin Wang, Experimental investigation of a dual-source powered absorption chiller based on gas engine waste heat and solar thermal energy, Energy, Volume 88, August 2015, Pages 680-689.

11. Z.Y. Xu, R.Z. Wang, H.B. Wang, Experimental evaluation of a variable effect $\mathrm{LiBr}-$ water absorption chiller designed for high-efficient solar cooling system, International Journal of Refrigeration, Volume 59, November 2015, Pages 135-143.

12. Raluca Porumb, Bogdan Porumb, Mugur Balan, Numerical Investigation on Solar Absorption Chiller with LiBr-H2O Operating Conditions and Performances, Energy Procedia, Volume 112, March 2017, Pages 108-117.

13. Evangelos Bellos, Christos Tzivanidis, Performance analysis and optimization of an absorption chiller driven by nanofluid based solar flat plate collector, Journal of Cleaner Production, Volume 174, 10 February 2018, Pages 256-272.

14. Qiyuan Li, Cheng Zheng, Ali Shirazi, Osama Bany Mousa, Design and analysis of a mediumtemperature, concentrated solar thermal collector for air-conditioning applications, Applied Energy, Volume 190, 15 March 2017, Pages 1159-1173.

15. A. Arabkoohsar, G.B. Andresen, Supporting district heating and cooling networks with a bifunctional solar assisted absorption chiller, Energy Conversion and Management, Volume 148, 15 September 2017, Pages 184-196.

16. A. Arabkoohsar, G.B. Andresen, A smart combination of a solar assisted absorption chiller and a power productive gas expansion unit for cogeneration of power and cooling, Renewable Energy, Volume 115, January 2018, Pages 489-500.

17. A. Arabkoohsar, L. Machado, R.N.N. Koury, Operation analysis of a photovoltaic plant integrated with a compressed air energy storage system and a city gate station, Energy, Volume 98, 1 March 2016, Pages 78-91.

18. Adewale Odukomaiya, Ahmad Abu-Heiba, Kyle R. Gluesenkamp, Omar Abdelaziz, Ayyoub M. Momen, Thermal analysis of near-isothermal compressed gas energy storage system, Applied Energy, Volume 179, 1 October 2016, Pages 948-960.

19. Stefano Briola, Paolo Di Marco, Roberto Gabbrielli, Juri Riccardi, A novel mathematical model for the 
performance assessment of diabatic compressed air energy storage systems including the turbomachinery characteristic curves, Applied Energy, Volume 178, 15 September 2016, Pages 758-772.

20. Hao Peng, Yu Yang, Rui Li, Xiang Ling, Thermodynamic analysis of an improved adiabatic compressed air energy storage system, Applied Energy, Volume 183, 1 December 2016, Pages 1361-1373.

21. A. Arabkoohsar, L. Machado, M. Farzaneh-Gord, R.N.N. Koury, Thermo-economic analysis and sizing of a PV plant equipped with a compressed air energy storage system, Renewable Energy, Volume 83, November 2015, Pages 491-509.

22. Marcus Budt, Daniel Wolf, Roland Span, Jinyue Yan, A review on compressed air energy storage: Basic principles, past milestones and recent developments, Applied Energy, Volume 170, 15 May 2016, Pages 250-268.

23. A. Arabkoohsar, M. Dremark-Larsen, R. Lorentzen, G.B. Andresen, Subcooled compressed air energy storage system for coproduction of heat, cooling and electricity, Applied Energy, Volume 205, 1 November 2017, Pages 602-614.

24. Yuanwei Lu, Wei He, Yuting Wu, Weining Ji, Performance study on compressed air refrigeration system based on single screw expander, Energy, Volume 55, 15 June 2013, Pages 762-768.

25. Corey T. Misenheimer, Stephen D. Terry, The development of a dynamic single effect, lithium bromide absorption chiller model with enhanced generator fidelity, Energy Conversion and Management, Volume 150, 15 October 2017, Pages 574-587.

26. Aarhus University Hospital (http://www.rm.dk).

27. AffaldVarme Aarhus - Waste and District Heating Aarhus (https://affaldvarme.aarhus.dk).

28. Jianyun Zhang, Pei Liu, Zhe Zhou, Linwei Ma, A mixed-integer nonlinear programming approach to the optimal design of heat network in a polygeneration energy system, Applied Energy, Volume 114, February 2014, Pages 146-154.

29. M. Farzaneh-Gord, A. Arabkoohsar, M. D. Dasht-bayaz, L. Machado, R. N. N: Koury, Energy and exergy analysis of natural gas pressure reduction points equipped with solar heat and controllable heaters, Renewable energy 72, 2014, pp: 258-270.

30. http://www.thermax-europe.com/index?locale=en

31. https://www.carrieraircon.co.uk/type/absorption-chillers/

32. https://www.greenmatch.co.uk/solar-energy

33. https://www.alibaba.com/

34. The Danish Levelized Cost of Energy Calculator, Danish Energy Agency (https://ens.dk/sites/ ens.dk/files/Globalcooperation/vejledning lcoe calculator.pdf).

35. Electrical Energy Storage, the IEC (https://www.iec.ch/whitepaper/pdf/iecWP-energystorage-LRen.pdf).

36. M. Farzaneh-Gord, A. Arabkoohsar, M. D. Dashtebayaz, A. A. Khoshnevis, New method for applying 
solar energy in greenhouses to reduce fuel consumption, International Journal of Agricultural and Biological Engineering 6 (4), 2013, pp: 64-75.

37. A. Ochoa, Energy and exergy analysis of the performance of 10 TR lithium bromide/water absorption chiller, Revista Técnica de la Facultad de Ingeniería Universidad del Zulia 37(1), 2014, pp: 38-47. 
1. A new hybrid configuration for trigeneration of heat, cold and electricity is proposed.

2. The system comprises a solar driven absorption chiller plus an electricity storage unit.

3. The operation of the electricity storage unit is determined via optimization methods.

4. The components of the hybrid system are sized based on techno-economic criteria.

5. The performance of the hybrid system is simulated and analyzed for a case study. 